\title{
Hydrous Nickel Oxide: Redox Switching and the Oxygen Evolution Reaction in Aqueous Alkaline Solution
}

M. E. G. Lyons, R. L. Doyle, I. Godwin, M. O'Brien and L. Russell

J. Electrochem. Soc. 2012, Volume 159, Issue 12, Pages H932-H944. doi: 10.1149/2.078212jes $\begin{array}{cl}\begin{array}{c}\text { Email alerting } \\ \text { service }\end{array} & \begin{array}{l}\text { Receive free email alerts when new articles cite this article - sign up } \\ \text { in the box at the top right corner of the article or click here }\end{array}\end{array}$

To subscribe to Journal of The Electrochemical Society go to: http://jes.ecsdl.org/subscriptions 


\title{
Hydrous Nickel Oxide: Redox Switching and the Oxygen Evolution Reaction in Aqueous Alkaline Solution
}

\author{
M. E. G. Lyons, R. L. Doyle, ${ }^{\mathrm{z}}$ I. Godwin, M. O'Brien, and L. Russell \\ Trinity Electrochemical Energy Conversion and Electrocatalysis (TEECE) Group, School of Chemistry \& CRANN, \\ Trinity College Dublin, Dublin 2, Ireland
}

\begin{abstract}
The redox switching reaction and the oxygen evolution reaction at multi-cycled nickel oxy-hydroxide films in aqueous alkaline solution are discussed. The hydrous oxide is considered as a porous assembly of interlinked octahedrally coordinated anionic metal oxyhydroxide surfaquo complexes which form an open network structure. The latter contains considerable quantities of water molecules which facilitate hydroxide ion discharge at the metal site during active oxygen evolution. The dynamics of redox switching has been quantified in terms of a diffusive frequency using the Laviron-Aoki diffusion model. Steady state Tafel plot analysis has been used to elucidate the kinetics and mechanism of oxygen evolution with slopes of ca. $60 \mathrm{mVdec}^{-1}$ and ca. $120 \mathrm{mVdec}^{-1}$ at low and high overpotentials respectively, whereas the reaction order with respect to hydroxide ion activity remains invariant at ca. 1.0 as the potential is increased. These observations are rationalized in terms of a kinetic scheme involving surfaquo groups. (C) 2012 The Electrochemical Society. [DOI: 10.1149/2.078212jes] All rights reserved.
\end{abstract}

Manuscript submitted August 17, 2012; revised manuscript received September 25, 2012. Published October 18, 2012. This was Paper 1395 presented at the Seattle, Washington, Meeting of the Society, May 6-10, 2012.

The oxygen evolution reaction (OER) is the anodic reaction that accompanies, in aqueous electrolytes, commerically important cathodic processes such as metal electrowinning and hydrogen production via alkaline water electrolysis. For the latter process, the anodic overpotential is the major factor in limting operational efficiency. ${ }^{1}$ The optimal oxygen evolution anode materials are $\mathrm{RuO}_{2}$ and $\mathrm{IrO}_{2}$, since these oxides exhibit the lowest overpotentials for the reaction at practical current densities. The high cost of these materials and their poor long term stability in alkaline solution, renders their widespread commercial utilization both uneconomical and impractical. ${ }^{2}$ Nickel and its alloys have therefore become the anodes of choice for water electrolysis. ${ }^{1,2}$ Although the OER overpotential is higher than for $\mathrm{RuO}_{2}$ or $\mathrm{IrO}_{2}$, nickel based electrodes are relatively inexpensive and display excellent corrosion resistance in aqueous alkaline media, and thus offer an attractive compromise solution. That said, the OER electrocatalytic performance of metallic $\mathrm{Ni}$ (actually passive oxide covered Ni) in alkaline solution diminishes markedly with time. ${ }^{3}$

In view of the latter considerations, there has been, over the past thirty years, extensive research focused on the development of OER electrocatalysts that display a combination of the desired characteristics of long term physical and chemical stability, satisfactorily low reaction overpotential and viable cost. Amongst the most promising materials that have been forwarded as OER anodes are, various intermetallic alloys (often containing significant amounts of $\mathrm{Ni}$, Co or $\mathrm{Fe}$ ), electrodeposited $\mathrm{Ni}\left(\mathrm{NiO}_{\mathrm{x}}\right)$ and $\mathrm{Co}\left(\mathrm{Co}_{3} \mathrm{O}_{4}\right)$ oxides, and mixed oxides, including spinels(particularly nickelites, cobaltites and ferrites) and perovskites. While the relatively high activity of nickel hydroxide electrodes for the OER is welcome in alkaline electrolyser applications, it is a drawback where this material is utilized as the positive electrode in secondary alkaline batteries (e.g. Ni-Cd, Ni-MH and Ni$\mathrm{MH}_{2}$ ) since it facilitates "self discharge" and consequently leads to a decrease of charge storage capacity. ${ }^{4,5}$ Thus in contrast to electrolyser anode research, work in the battery area has been directed toward increasing the OER overpotential at nickel hydroxide electrodes. This has been achieved by the addition of cobalt hydroxide to the nickel hydroxide,${ }^{6}$ however, depending on the amount of incorporated Co, this procedure can actually improve OER catalytic activity. ${ }^{7}$ These oxides have been prepared from inorganic precursor materials using a wide variety of approaches, including thermal decomposition, spray pyrolysis, sol-gel routes and freeze drying, precipitation or electrodeposition from solution.

Despite all this intense activity the mechanism of the OER at first row transition metal oxide surfaces remains controversial. The experimental confirmation that a common OER mechanism pertains for these materials would be a significant aid in the eventual develop-

${ }^{\mathrm{z}}$ E-mail: rdoyle5@tcd.ie ment of a general predictive theory of OER electrocatalysis for such materials.

In the present paper we examine the mechanism both of redox switching and anodic oxygen evolution at oxidized nickel electrodes in alkaline solution using a combination of steady state polarization techniques and reaction order studies. We propose a mechanism for the latter which specifically takes the nature of the electrochemically generated hydrous oxide film that is present on the surface of the $\mathrm{Ni}$ electrode during active oxygen evolution into account. This work follows on from our recently published studies on the interfacial redox chemistry, redox switching mechanism and OER electrocatalytic activity of oxidized transition metal electrodes ${ }^{8-10}$ and iron electrodes modified with microdispersed hydrous oxy hydroxide films. ${ }^{11-16}$

\section{Experimental}

All experiments were conducted in a conventional three electrode cell. The working electrode was constructed from $1 \mathrm{~mm}$ thick polycrystalline nickel foil (as supplied by Alfa Aesar-Johnson Matthey, purity $99.9945 \%$ (metals basis)) with a geometric surface area of $0.16 \mathrm{~cm}^{2}$. Prior to each experiment the surface of the working electrode was polished with 1200 grit carbimet paper, dipped in $\mathrm{H}_{2} \mathrm{SO}_{4}$, wiped, and polished with a slurry of 0.3 micron alumina powder until a "mirror bright" finish was achieved. A platinum wire electrode $(\mathrm{CH}$ Instruments, cat no. CHI 115) was employed as the counter electrode and a mercury-mercuric oxide $(\mathrm{Hg} / \mathrm{HgO})$ reference electrode $(\mathrm{CH} \mathrm{In}$ struments, cat no. CHI 152) was utilized as the reference standard, therefore all voltages are quoted against this reference electrode. ${ }^{1}$ When used in $\mathrm{NaOH}$ solutions of different concentrations, the potential of the $\mathrm{Hg} / \mathrm{HgO}$ electrode was checked relative to a second $\mathrm{Hg} / \mathrm{HgO}, 1.0 \mathrm{~mol} \mathrm{dm}^{-3} \mathrm{NaOH}$ electode, both before and after the experiment. No significant potential drift was noted after such experiments, implying that the concentration of the $\mathrm{NaOH}$ in the reference electrode chamber remains effectively constant over the time scale of typical polarization measurements. In any case, the $1.0 \mathrm{~mol} \mathrm{dm}^{-3}$ $\mathrm{NaOH}$ solution in the reference electrode, was changed regularly to ensure experimental consistency.

Aqueous $\mathrm{NaOH}$ solutions (in the range between 0.1 and $5.0 \mathrm{~mol} \mathrm{dm}^{-3}$ ) served as both the electro-polymerisation medium and the supporting electrolyte for the redox switching and electrocatalytic

\footnotetext{
${ }^{1}$ The equilibrium potential of the cell $\mathrm{Pt} / \mathrm{H}_{2} / \mathrm{OH}^{-} / \mathrm{HgO} / \mathrm{Hg}$ is $0.926 \mathrm{~V}$ at $298 \mathrm{~K}$. Since the equilibrium oxygen electrode potential is $1.229 \mathrm{~V}$ vs RHE, it follows that the corresponding value is $0.303 \mathrm{~V}$ vs $\mathrm{Hg} / \mathrm{HgO}$ in the same solution. Hence $\mathrm{E}_{\mathrm{Hg} / \mathrm{HgO}}=\mathrm{E}_{\mathrm{RHE}}-0.926 \mathrm{~V}$. It is common practice in the literature on the OER to express potential in terms of the oxygen overpotential $\eta$, when the reference electrode is a $\mathrm{Hg} / \mathrm{HgO}$ electrode in the same solution as the working anode. Clearly, in this case the overpotential $\eta$ is related to $E_{\text {meas }}$ measured on the $\mathrm{Hg} / \mathrm{HgO}$ scale as follows: $\eta=\mathrm{E}_{\text {meas }}-0.303 \mathrm{~V}$ (at $\mathrm{T}=298 \mathrm{~K}$ ).
} 
studies. This solution was prepared from sodium hydroxide pellets (Sigma-Aldrich, minimum 99\% purity) using Millipore water (resistivity $>15 \mathrm{M} \Omega \mathrm{cm}$ ). Before commencing each experiment, nitrogen gas was bubbled through the electrolyte solution for $20 \mathrm{~min}$.

The electrochemical measurements were performed using a number of high performance digital potentiostats including a BAS $100 \mathrm{~B}$ Electrochemical Analyser and a CH Model 760 D Bi-potentiostat system. Both workstations were controlled by high end desktop Personal Computers (Dell). The uncompensated solution resistance was determined using a method developed by He and Faulkner. ${ }^{17}$ Typically the uncompensated solution resistance (90\% compensation level) varies from ca. $0.30 \Omega$ for $\left[\mathrm{OH}^{-}\right]=5.0 \mathrm{~mol} \mathrm{dm}{ }^{-3}$ to ca. $4.3 \Omega$ for $\left[\mathrm{OH}^{-}\right]$ $=0.1 \mathrm{~mol} \mathrm{dm}^{-3}$. This parameter was specifically considered in the Tafel plot measurements, where the data is presented in $i R$ compensated form. Unless otherwise specified, all values of current density are normalized with respect to the geometric surface area.

Charge storage capacities (redox capacities), $Q$, were determined via integration of the peaks recorded in the voltammetric profiles at slow sweep rates. The redox capacity is directly proportional to the layer thickness. The polymeric Ni oxy-hydroxide films were prepared via multi-cycling the Ni electrode between the switching potentials of $-1.450 \mathrm{~V}$ and $0.65 \mathrm{~V}$ at a scan rate of $0.15 \mathrm{~V} \mathrm{~s}^{-1}$. Films of different thicknesses were prepared by varying the number of growth cycles. The charge storage capacity or redox capacity (Q) was determined, following the growth of each film, by integration of the peaks in a voltammetric profile recorded at a slow sweep rate $\left(40 \mathrm{mV} \mathrm{s}^{-1}\right)$. The redox capacity is directly proportional to the layer thickness. Tafel plots were recorded for each film using linear sweep voltammetry performed at a sweep rate of $1 \mathrm{mV} \mathrm{s}^{-1}$.

\section{Results and Discussion}

Hydrous Oxide Growth via repetitive potential sweep multicycling (RPSM).- - It has been commented by Gottesfeld and Srinivasan that "the "science" of the OER is a "science" of the oxides and their properties". ${ }^{18}$ We agree that this statement is particularly pertinent for Ni electrochemistry in base. Potential cycling is one of the most versatile and convenient techniques that can be used to generate hydrous oxides in a form suitable for the real time determination of their redox switching and electrocatalytic behavior. In this method the potential of an electrode of the parent metal (which may be noble or non-noble) is cycled repetitively between suitable lower and upper limits in an aqueous solution of appropriate $\mathrm{pH}$. The type of potential perturbation used for oxide growth - sinusoidal, square or triangular wave- apparently makes little difference. Indeed the triangular wave is most convenient as changes in the current vs. potential response (the voltammogram) can be employed during the oxide growth reaction to monitor changes in redox behavior associated with the latter. ${ }^{19}$ That said, Arvia and co-workers ${ }^{20}$ contend that a repetitive square wave potential pulse is also very effective for the controlled generation of hydrated metal oxy-hydroxide films on metallic supports, especially if one wishes to form relatively thick oxide films.

Cyclic voltammograms recorded during the growth of a hydrous oxide film on an initially bright $\mathrm{Ni}$ substrate in $1.0 \mathrm{~mol} \mathrm{dm}^{-3} \mathrm{NaOH}$ are presented in Fig. 1. The growth of the film is evident from the set of redox peaks located in the potential region $0.40-0.50 \mathrm{~V}$ vs. $\mathrm{Hg} / \mathrm{HgO}$ which become increasingly more developed with increasing number of potential cycles. The integrated charge developed under either the anodic or cathodic peak can be used as a measure of oxide film thickness. The variation of oxide charge capacity $Q$ with number of oxide growth cycles $\mathrm{N}$ is presented in Fig. 2. The oxide growth kinetics can be fit to the following empirical expression:

$$
Q=a(1-\exp [-b N])
$$

where $a$ and $b$ are empirical constants with numerical values determined via NLLS fitting predicted as $a=0.0014 \pm 7.43 \times 10^{-5} C$ and $b=0.045 \pm 0.0004$ cycle $^{-1}$. Hence the oxide growth rate gradually decreases with increasing number of growth cycles and the charge

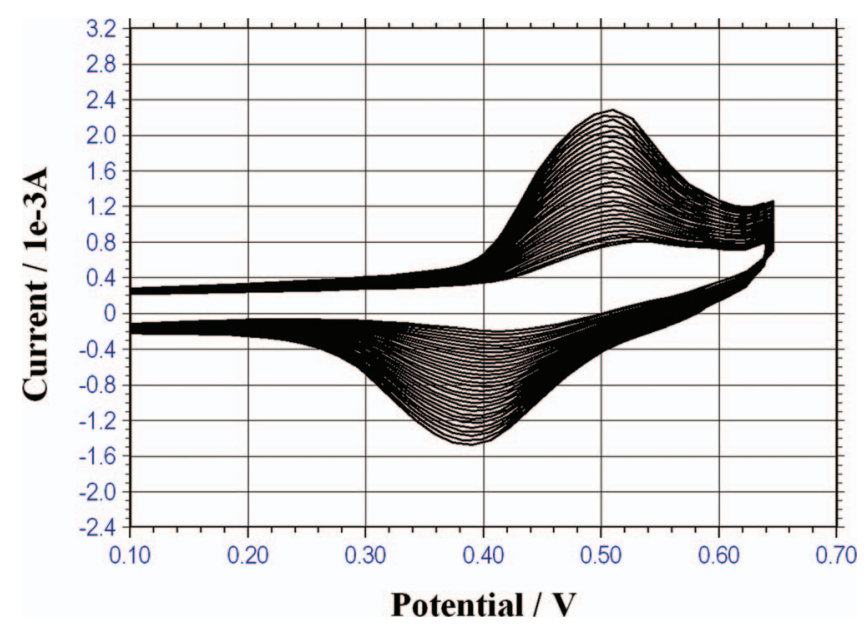

Figure 1. Growth of hydrous nickel oxide thin film on Ni support electrode monitored via analysis of the evolution of the real time voltammogram in $1.0 \mathrm{M} \mathrm{NaOH}$. Growth potential limits: -1.45 to $0.65 \mathrm{~V}$ (vs $\mathrm{Hg} / \mathrm{HgO})$, sweep rate $150 \mathrm{mV} / \mathrm{s}$.

capacity $\mathrm{Q}$ approaches a constant limiting value as $\mathrm{N}$ gets large, i.e. $Q \rightarrow a$ as $N \rightarrow \infty$.

A characteristic feature of the voltammetric response of multicycled oxidized nickel electrodes in aqueous base, as shown in Fig. 3 and Fig. 4, is a well defined set of peaks located at potentials just prior to the onset of active oxygen gas evolution. These redox peaks, corresponding to a $\mathrm{Ni}(\mathrm{II} / \mathrm{III})$ redox transition within the deposited hydrous oxide film, may exhibit some fine structure. The voltammetric response recorded for a multicycled nickel electrode $(\mathrm{N}=30$ cycles $)$ in $1.0 \mathrm{~mol} \mathrm{dm} \mathrm{dm}^{-3}$ base is presented in Fig. 3 whereas the corresponding profile for an electrode after 120 cycles is outlined in Fig. 4. For the thinner nickel oxy-hydroxide film (Fig. 3) an anodic peak $\left(\mathrm{A}_{2}\right)$ at $0.48 \mathrm{~V}$ and an anodic shoulder $\left(\mathrm{A}_{2}{ }^{\prime}\right)$ at $0.54 \mathrm{~V}$ may be observed during the forward oxidative sweep whereas on the reverse reductive sweep two cathodic peaks are visible, the first (labeled $\mathrm{C}_{2}$ ) located at $0.46 \mathrm{~V}$ and the second $\left(\mathrm{C}_{2}{ }^{\prime}\right)$ at $0.36 \mathrm{~V}$. In contrast only a single well defined anodic peak $\left(\mathrm{A}_{2}\right)$ is observed at $0.50 \mathrm{~V}$ during the oxidative sweep and a well resolved cathodic doublet at potentials of ca. $0.44 \mathrm{~V}\left(\mathrm{C}_{2}\right)$ and $0.34 \mathrm{~V}\left(\mathrm{C}_{2}{ }^{\prime}\right)$ for the thicker oxide films (Fig. 4).

In a recent publication ${ }^{21}$ we showed that a distinct pair of peaks, designated as $A_{1}$ and $C_{1}$, may be discerned when Ni electrodes are subjected to a potential sweep in the region -1.2 to $-0.20 \mathrm{~V}$ in $1.0 \mathrm{~mol}$

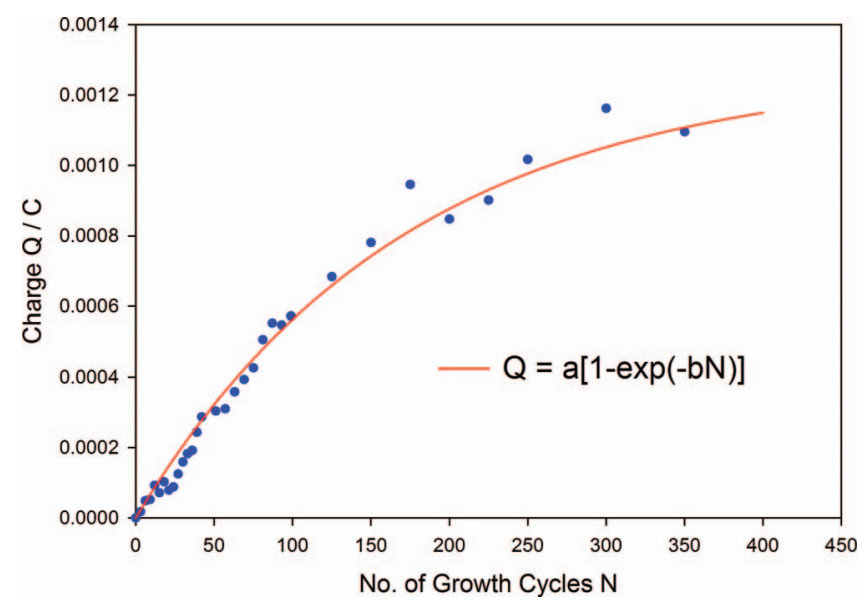

Figure 2. Growth of hydrous nickel oxide thin film on Ni support electrode monitored via analysis of the evolution of the real time voltammogram in $1.0 \mathrm{M} \mathrm{NaOH}$. Plot of integrated voltammetric charge $\mathrm{Q}$ (measured at $40 \mathrm{mV} / \mathrm{s}$ ) as a function of oxide growth cycles $\mathrm{N}$. 


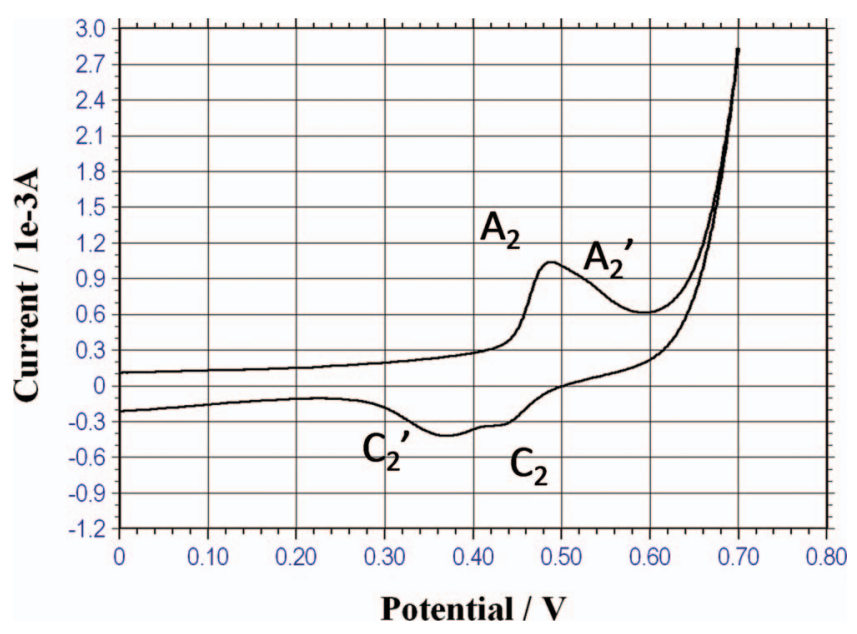

Figure 3. Typical voltammetric response recorded for a hydrous nickel oxyhydroxide thin film on $\mathrm{Ni}$ support electrode grown in aqueous $1.0 \mathrm{M} \mathrm{NaOH}$ for $\mathrm{N}=30$ cycles. Sweep rate, $40 \mathrm{mV} / \mathrm{s}$.

$\mathrm{dm}^{-3} \mathrm{NaOH}$. The initial stage of oxide growth involves the formation of a compact nickel oxide film. It is almost universally agreed that the lower anodic peak observed in the potential region between $-0.6 \mathrm{~V}$ and $-0.8 \mathrm{~V}$ is principally associated with the oxidation of metallic $\mathrm{Ni}(0)$ to $\mathrm{Ni}(\mathrm{II})$ species. By analogy with the situation found at low potentials for $\mathrm{Fe}$ in base ${ }^{15,16}$ we can visualize the following sequence of reactions at low potentials:

$$
\begin{gathered}
\mathrm{Ni}+\mathrm{OH}^{-} \rightarrow \mathrm{NiOH}_{(\text {ads. })}+\mathrm{e}^{-} \\
\mathrm{NiOH}_{(\text {ads. })}+\mathrm{OH}^{-} \rightarrow \mathrm{Ni}(\mathrm{OH})_{2}+\mathrm{e}^{-} \\
\mathrm{NiOH}_{\text {(ads. })}+\mathrm{OH}^{-} \rightarrow \mathrm{NiO}_{(\text {ads })}+\mathrm{H}_{2} \mathrm{O}+\mathrm{e}^{-}
\end{gathered}
$$

The overall interfacial reaction resulting in $\mathrm{Ni}(\mathrm{II})$ film formation may be more complex than that outlined above due to a variety of other possible reactions. ${ }^{21}$ When the anodic limit of the potential sweep was maintained well below the upper redox charge storage peaks, Burke and Twomey ${ }^{22}$ observed a $\mathrm{pH}$ invariant cathodic peak at potentials some $0.3 \mathrm{~V}$ lower than the anodic peak. We have observed similar peaks as recently noted. ${ }^{21}$ Furthermore, peaks $\mathrm{A}_{1}$ and $\mathrm{C}_{1}$ can be observed at potentials in the region -0.6 to $-1.0 \mathrm{~V}(\mathrm{vs} \mathrm{Hg} / \mathrm{HgO})$ irregardless of whether the nickel electrode has been subjected to a potential multicycling perturbation or not. However, the cathodic peak

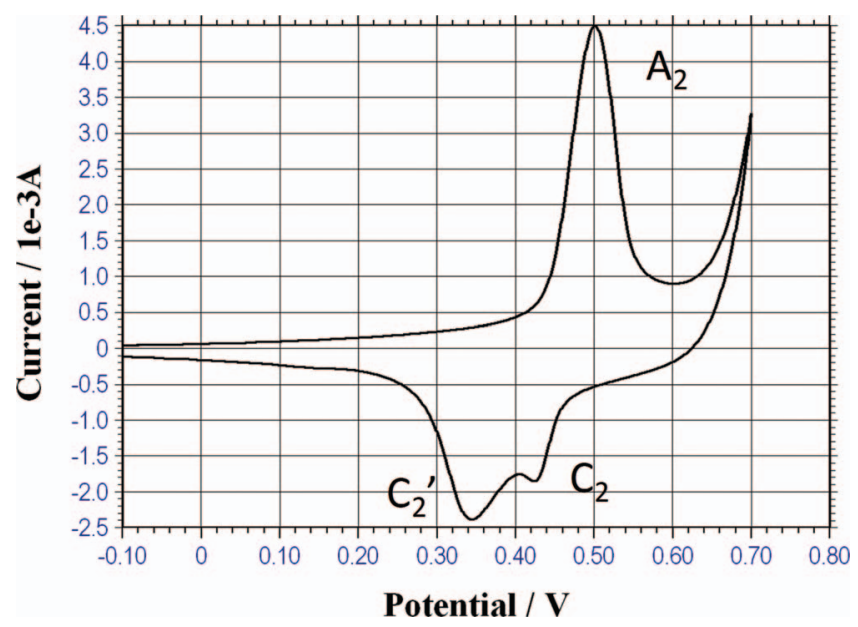

Figure 4. Typical voltammetric response recorded for a hydrous nickel oxyhydroxide thin film on $\mathrm{Ni}$ support electrode grown in aqueous $1.0 \mathrm{M} \mathrm{NaOH}$ for $\mathrm{N}=120$ cycles. Sweep rate, $40 \mathrm{mV} / \mathrm{s}$.
$\mathrm{C}_{1}$ is only observed if the upper limit of the potential sweep is reversed at a potential (ca. $-0.2 \mathrm{~V}$ ) far from the onset of the development of the main charge storage peaks (the latter occur at $\mathrm{E}>0.2 \mathrm{~V}$ ). Based on the variation of the voltammetric peak potential with changes in $\mathrm{pH}$ in alkaline solution (typically the redox potential for the anodic reaction decreases by ca. $13 \mathrm{mV}$ per unit change in $\mathrm{pH}$ with respect to a $\mathrm{pH}$ independent reference electrode), Burke and Twomey ${ }^{22}$ proposed that both oxidation and hydrolysis processes were operative in this region, leading to the formation of a species with anionic character which was tentatively assigned, for purposes of rationalization, the formula $\mathrm{Ni}(\mathrm{OH})_{2.4}{ }^{0.4-}$. The reaction sequence proposed by the latter workers was:

$$
\begin{gathered}
\mathrm{Ni}+2 \mathrm{OH}^{-} \rightarrow \mathrm{Ni}(\mathrm{OH})_{2}+2 \mathrm{e}^{-} \\
\mathrm{Ni}(\mathrm{OH})_{2}+\left[\mathrm{NiO}_{0.4}(\mathrm{OH})_{1.6}\right]^{0.4-}+0.4 \mathrm{H}^{+}
\end{gathered}
$$

Note that eqn. 6 may be represented as a hydroxide ion adsorption step since the reaction occurs in alkaline solution:

$$
\mathrm{Ni}(\mathrm{OH})_{2}+0.4 \mathrm{OH}^{-} \rightarrow \mathrm{Ni}(\mathrm{OH})_{2.4}{ }^{0.4-}
$$

Hence in very simple terms the net anodic reaction corresponding to peak $A_{1}$ can be represented as:

$$
\mathrm{Ni}+2.4 \mathrm{OH}^{-} \rightarrow\left[\mathrm{Ni}(\mathrm{OH})_{2.4}\right]^{0.4-}
$$

As previously stated, a $\mathrm{pH}$ invariant cathodic peak $\mathrm{C}_{1}$ can be observed at potentials some $0.3 \mathrm{~V}$ lower than $\mathrm{A}_{1}$ when the anodic limit of the potential sweep was maintained well below the upper redox charge storage peaks. ${ }^{22}$ We agree with the conclusion proposed by Burke and Twomey ${ }^{22}$ that the reversal in sweep direction at low potentials causes the initially produced hydrous oxide species to transform to a more anhydrous form, such as to $\mathrm{NiO}$ say. Hence the $\mathrm{C}_{1}$ reduction peak could be due to:

$$
\mathrm{NiO}+\mathrm{H}_{2} \mathrm{O}+2 \mathrm{e}^{-} \rightarrow \mathrm{Ni}+2 \mathrm{OH}^{-}
$$

In essence the Burke-Twomey ${ }^{22}$ proposal is that due to post electrochemical place exchange reactions, the anionic oxide becomes neutral before being reduced back to Ni metal. They also suggest that the lower oxidation peak appears to be superimposed on a background current that is probably due to a combination of adsorbed hydrogen oxidation and formation of a layer of adsorbed hydroxyl species. In an ellipsometric study de Souza et al. ${ }^{23}$ found that the first layer of oxide formed at potentials close to the lower anodic peak $\mathrm{A}_{1}$ consists of $\mathrm{NiO}$. However this becomes covered with a thick film of $\mathrm{Ni}(\mathrm{OH})_{2}$ upon further increase of potential. A further significant observation of Burke and Twomey ${ }^{22}$ was that the magnitude and position of the lower anodic peak did not alter much with repetitive potential cycling. Our previously reported data ${ }^{21}$ support this observation. We therefore support the Burke-Twomey ${ }^{22}$ contention that it is the inner, compact oxide layer that is reduced at significant cathodic potentials, and thus, even on cycling, the $\mathrm{A}_{1}$ peak is associated with oxidation of $\mathrm{Ni}$ metal to $\mathrm{Ni}$ (II) at the metal/porous hydrous oxide interface.

It is worth noting here that, although directly produced in the initial electrochemical oxidation process, the anhydrous film is probably not the most stable metal oxidation product in the aqueous medium. Instead it may be regarded as an intermediate or metastable product in the formation of a hydrous oxide layer. ${ }^{24}$ In the anhydrous film ions are held in a rigid manner in an extended network of polar covalent bonds which drastically reduce ion transport through (and consequently extension of) the surface layer. The next stage of the film thickening process, the hydration reaction, is generally very slow, because as in phase transformation reactions, it involves rupture of primary coordination metal-oxygen bonds. We have shown ${ }^{24}$ that the extent of hydrous oxide growth depends strongly on the value chosen for the upper and lower limit of the potential sweep as well as on the cycling frequency adopted, the solution temperature and the solution $\mathrm{pH}$.

The marked dependence of oxide growth rate on the lower limit of the potential sweep (found for a wide number of noble and non-noble transition metals) is indicative of the essential role that partial reduction of the anhydrous oxide plays in the production of a thick deposit. 


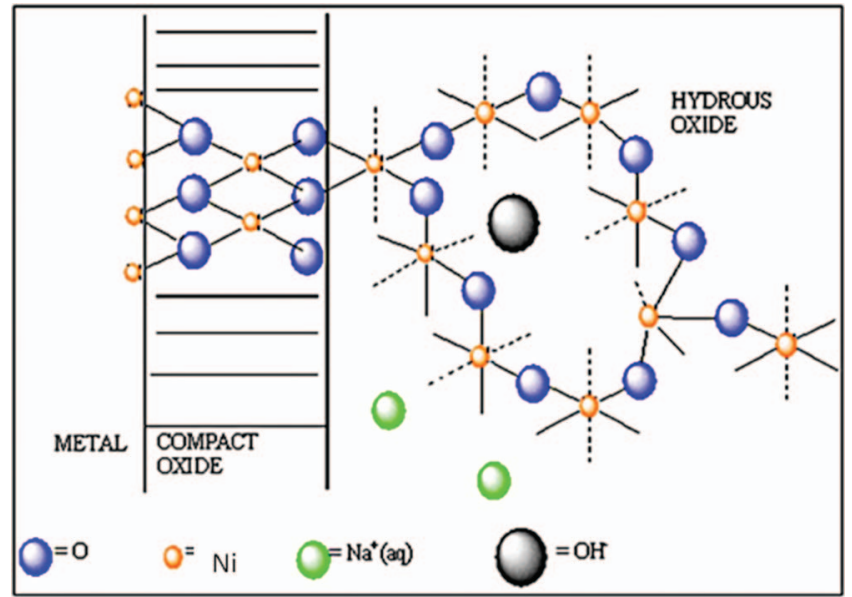

Figure 5. Duplex layer model of oxide/solution interface region following Burke and O'Sullivan. ${ }^{29}$

Partial reduction of the compact oxide layer apparently facilitates rearrangement of oxycation species at the metal surface, leaving it in a somewhat disrupted state. It is established that in the case of both platinum $^{25}$ and gold ${ }^{25,26}$ the anhydrous film is reduced much more readily than the hydrated film. The greater stability of the latter is possibly due to a variety of reasons such as lower repulsion between cations owing to greater separation and decreased charge (the latter effect being due to hydroxyl ion coordination by cations present) and polymer formation. Indeed it has been established that in the case of metal-gas interactions ${ }^{27}$ the adsorption-desorption process affects displacement of atoms in the outer layer of the metallic phase, and that potential cycling causes roughening of the surface of noble metals such as platinum under certain conditions. ${ }^{28}$

Upon re-oxidation of the partially reduced metal surface the compact layer is restored. However, the outer region of the compact film is now present in a more dispersed form. On further reduction the latter material becomes incorporated into the hydrated outer layer. It is not clear whether this rearrangement process involves detachment of oxycations, i.e. a dissolution-reprecipitation mechanism, or a certain weakening, with only a partial detachment of oxycation binding in the compact oxide layer. In the latter case the partially reduced cations are assumed to be displaced from normal lattice sites, and, as such, are more susceptible to oxidation in the subsequent anodic sweep during which they complete their oxygen coordination shell of six oxygen atoms to form a rather open polymeric inorganic bronze or zeolite type structure. Hence under conditions of thick film growth the interfacial region may be represented by: $\mathrm{M} / \mathrm{MO}_{\mathrm{x}} / \mathrm{MO}_{\mathrm{a}}(\mathrm{OH})_{\mathrm{b}}\left(\mathrm{OH}_{2}\right)_{\mathrm{c}}$ /aqueous phase as is outlined in Fig. 5. This is the duplex layer model of the oxide/solution interphase region. Here $\mathrm{MO}_{\mathrm{x}}$ represents the inner compact layer and $\mathrm{MO}_{\mathrm{a}}(\mathrm{OH})_{\mathrm{b}}\left(\mathrm{OH}_{2}\right)_{\mathrm{c}}$ denotes the outer hydrous layer. This model was first suggested by Burke and O'Sullivan. ${ }^{29}$ Hence the appearence of the lower anodic peak $A_{1}$ and the enhanced hydrous oxide growth reaction (see Fig. 6 for example) only occur under potential cycling conditions when the lower limit of the potential sweep is set at a magnitude sufficiently cathodic to ensure extensive reduction at the compact/support electrode interface.

The interfacial redox chemistry of the multicycled nickel oxide electrode in aqueous alkaline solution can be readily understood in terms of the Bode scheme of squares. ${ }^{30}$ Here the redox switching behavior of electrochemically generated nickel oxide films was rationalized in terms of four phases as outlined in Fig. 7. The discharged or reduced $\mathrm{Ni}(\mathrm{OH})_{2}$ material can exist either as a largely anhydrous phase designated as $\beta-\mathrm{Ni}(\mathrm{OH})_{2}$ (denoted $\beta-\mathrm{Ni}(\mathrm{II})$ ) or as a hydrated phase denoted as $\alpha-\mathrm{Ni}(\mathrm{OH})_{2}$ (in short represented as $\alpha-\mathrm{Ni}(\mathrm{II})$ ). Oxidation of the $\beta-\mathrm{Ni}(\mathrm{II})$ material is envisaged to produce a phase referred to as $\beta-\mathrm{NiOOH}$ or $\beta-\mathrm{Ni}(\mathrm{III})$. In contrast oxidation of the $\alpha-\mathrm{Ni}(\mathrm{II})$ material produces $\gamma-\mathrm{Ni}(\mathrm{III})$ or $\gamma-\mathrm{NiOOH}$. Hence one expects two distinct re-

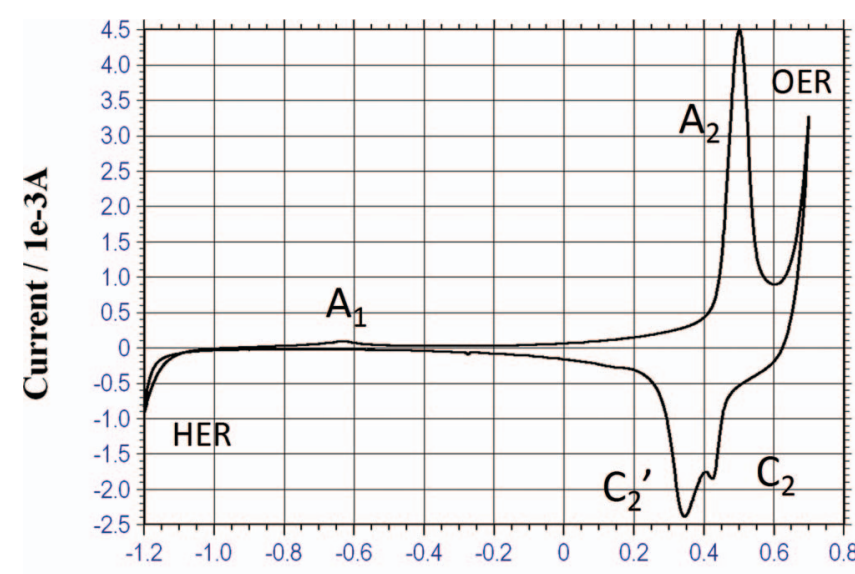

Potential / V

Figure 6. Typical voltammetric response recorded for a hydrous nickel oxyhydroxide thin film on $\mathrm{Ni}$ support electrode grown in aqueous $1.0 \mathrm{M} \mathrm{NaOH}$ for $\mathrm{N}=120$ cycles. Sweep rate, $40 \mathrm{mV} / \mathrm{s}$. Voltammetric response recorded between limits of hydrogen and oxygen evolution.

dox transitions : $\beta$ (II) $/ \beta(\mathrm{III})$ and $\alpha(\mathrm{II}) / \gamma(\mathrm{III})$. The corresponding redox peaks are designated $\mathrm{A}_{2}{ }^{\prime} / \mathrm{C}_{2}{ }^{\prime}$ and $\mathrm{A}_{2} / \mathrm{C}_{2}$ respectively.

It can be noted from Fig. 7 that upon aging the $\alpha-\mathrm{Ni}(\mathrm{OH})_{2}$ can dehydrate and re-crystallize as $\beta-\mathrm{Ni}(\mathrm{OH})_{2}$. This is especially prevalent in more concentrated alkali solution. In addition, overcharging $\beta-\mathrm{NiOOH}$ (which occurs at more elevated potentials) can convert it to $\gamma-\mathrm{NiOOH}$. The non-stoichiometric nature of both the discharged and charged material is indicated by the average oxidation state of $\mathrm{Ni}$ in each phase as indicated in the structural representation of the various phases in Fig. 7. It is important to note that while there is a general acceptance for the general features of the Bode scheme, one must understand that it is inappropriate to think about the formation of a compound or a phase with definite stoichiometry during the chemically complex $\mathrm{Ni}(\mathrm{OH})_{2} / \mathrm{NiOOH}$ transformation. Instead the four phases mentioned in the Bode scheme should be considered as the limiting forms of the divalent and trivalent materials - the actual composition of the oxide at a given potential depending on a range of factors including its history, method of preparation, degree of hydration, defect concentration etc.

Burke and Lyons ${ }^{24}$ have shown that, for an ideal oxide electrode system in aqueous solution at $25^{\circ} \mathrm{C}$, the potential decreases with

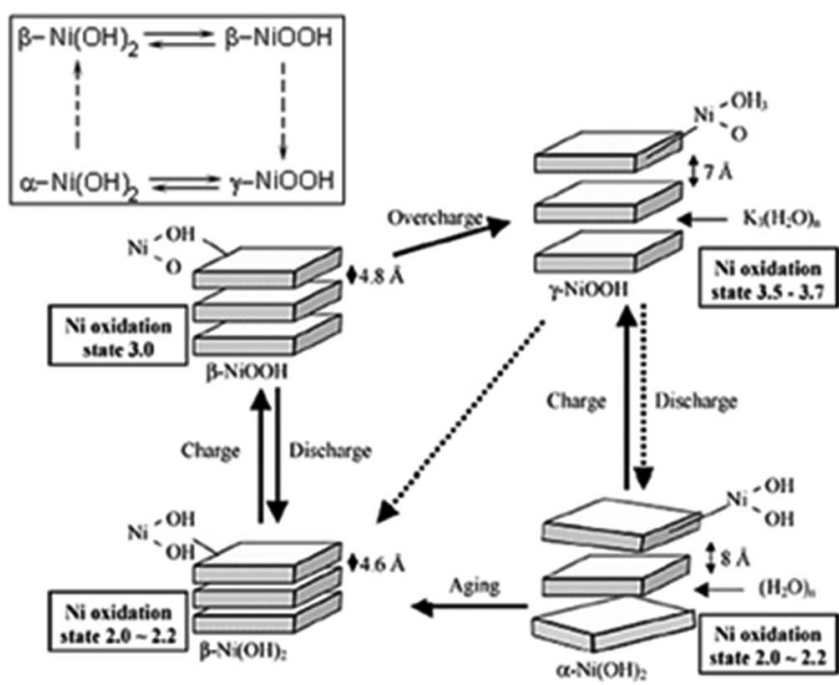

Figure 7. Representation of simple Bode Scheme of Squares for nickel oxide. 


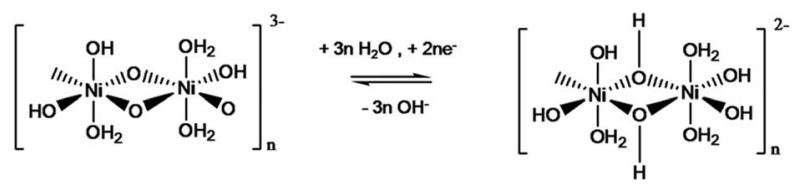

Scheme A.

increasing $\mathrm{pH}$ by ca. $59 \mathrm{mV} / \mathrm{pH}$ unit with respect to a $\mathrm{pH}$ independent reference electrode such as the NHE or the saturated calomel electrode (SCE). Such a potential-pH shift is referred to as a Nernstian shift, since it is predicted by the Nernst equation. Alternatively, if the reference electrode is $\mathrm{pH}$ dependent, such as the reversible hydrogen electrode (RHE) or the $\mathrm{Hg} / \mathrm{HgO}$ electrode, no potential $\mathrm{pH}$ shift will be observed, since the potential of this type of electrode also alters by ca. $59 \mathrm{mV}$ per unit change in $\mathrm{pH}$ at $25^{\circ} \mathrm{C}$. Furthermore, Burke and Lyons ${ }^{24}$ have discussed super-Nernstian shifts that have been observed for various hydrous oxide systems - in these cases the potential/pH shift differs from the expected $0.059 \mathrm{~V} / \mathrm{pH}$ unit at $25^{\circ} \mathrm{C}$. The mathematical treatment of this situation is beyond the scope of the present paper, but suffice to say, the phenomena have recently been qualitatively summarized. ${ }^{30}$ Thus, a zero potential shift (with respect to a $\mathrm{pH}$ dependent reference electrode) implies that both the reactants and the product possess the same net charge. A positive potential shift with $\mathrm{pH}$, is indicative of an oxidized state that is more positive than the reduced state, whereas the converse is true in the case of an observed negative potential/pH shift.

The voltammetric profiles and the individual $\mathrm{A}_{2}, \mathrm{C}_{2}$ and $\mathrm{C}_{2}{ }^{\prime}$ peak potentials are presented in Fig. 8. Note that peak $\mathrm{A}_{2}^{\prime}$ was not observed. As previously shown ${ }^{30}$ that the anhydrous $\mathrm{A}_{2}{ }^{\prime} / \mathrm{C}_{2}^{\prime}$ peaks exhibit a regular Nernstian shift whereas the hydrous counterparts $\mathrm{A}_{2} / \mathrm{C}_{2}$ exhibit the characteristic of a hydrous or hyper-extended oxide, ${ }^{30}$ i.e. a supernernstian potential-pH shift, which typically has the value of $\mathrm{d} E / \mathrm{d} p H$ $=-2.303(3 R T / 2 F)=-0.088 \mathrm{~V} / \mathrm{pH}$ unit at $\mathrm{T}=298 \mathrm{~K}$. Accordingly, by analogy with a scheme produced by Burke and Whelan ${ }^{31}$ for redox switching of iridium oxide films, it has been proposed that the main redox switching reaction (corresponding to the peak set $A_{2} / C_{2}$ ) may be written as:

$$
\begin{aligned}
& {\left[\mathrm{Ni}_{2}(\mathrm{OH})_{6}\left(\mathrm{OH}_{2}\right)_{3}\right]_{n}{ }^{2-}+3 \mathrm{nOH}^{-}} \\
& \quad \rightarrow\left[\mathrm{Ni}_{2} \mathrm{O}_{3}(\mathrm{OH})_{3}\left(\mathrm{OH}_{2}\right)_{3}\right]_{n}{ }^{3-}+3 \mathrm{nH}_{2} \mathrm{O}+2 \mathrm{ne}^{-}
\end{aligned}
$$

corresponding to an $\mathrm{Ni}(\mathrm{II}) / \mathrm{Ni}(\mathrm{III})$ redox transition in a polymeric microdispersed hydrous oxide layer. This redox switching reaction is illustrated schematically in Scheme A.
Dynamics of redox switching.- We now consider the results of a series of experiments, conducted to quantify the rate of charge percolation through the hydrated layer. The redox switching reaction (associated with the $A_{2} / C_{2}$ voltammetric peaks) reflects the change in oxidation state of the film as a result of a potential perturbation. Redox centers immediately adjacent to the support electrode are directly affected by the electrode potential, whereas charge is further propagated along the oxy-nickel polymer strands in the hydrous layer via a sequence of electron self exchange reactions between neighboring oxy-metal sites. This process is envisaged to be analogous to redox conduction exhibited by electroactive polymer films. In the simplest terms this electron "hopping" may be modeled in terms of a diffusional process, and so the charge percolation rate may be quantified in terms of a charge transport diffusion coefficient, $D_{C T}$. In the case of hydrous nickel oxide, the latter may reflect either the electron hopping rate or the diffusion of of $\mathrm{OH}^{-}$(or equivalently $\mathrm{H}_{3} \mathrm{O}^{+}$) ions via a rapid Grotthus type mechanism. The charge transport diffusion coefficient may be quantitatively estimated using cyclic voltammetry.

As previously noted the charge/discharge reaction involving a $\mathrm{Ni}(\mathrm{II}) / \mathrm{Ni}(\mathrm{III})$ redox transition within the hydrous oxide is simplistically viewed as a $\mathrm{Ni}(\mathrm{OH})_{2} / \mathrm{NiOOH}$ transition of the type outlined in eqn. 10. MacArthur, ${ }^{32}$ Zimmerman and Effa, ${ }^{33}$ Weidner and coworkers, ${ }^{34}$ and Mao et al. ${ }^{35}$ have suggested that the charge/discharge process is controlled by the diffusion of protons. We suggest that the latter occurs within the hydrated layer. Hence during discharge a proton diffuses from the film/electrolyte interface into the hydrous oxide region and an electron enters across the conducting compact oxide/hydrous film interface. During charging the proton diffuses to the film/electrolyte interface to react there with hydroxyl ions to form water. This idea is presented schematically in Fig. 9. EQCM measurements have also indicated that redox switching is accompanied by cation transport through the solution filled pores between the polymer strands of the oxide film..$^{36-38}$ It should be noted however that much of the analysis of mass transport within nickel oxide thin films has dwelt on the electoprecipitated oxide and so the conclusions derived from these EQCM studies may not totally apply to the hydrous microdispersed nickel oxyhydroxide variant.

We now examine the redox switching behavior of the hydrated nickel oxide electrode in aqueous base to a potential sweep perturbation. Although we have noted in a previous communication ${ }^{21}$ that the redox switching process may be somewhat more complex, we will attempt to apply a simple first order finite diffusion model to obtain quantitative transport information pertaining to the proton diffusion coefficient through the hydrous layer. In the present work we utilize the mathematical formalism of Aoki and co-workers ${ }^{39}$ and extended
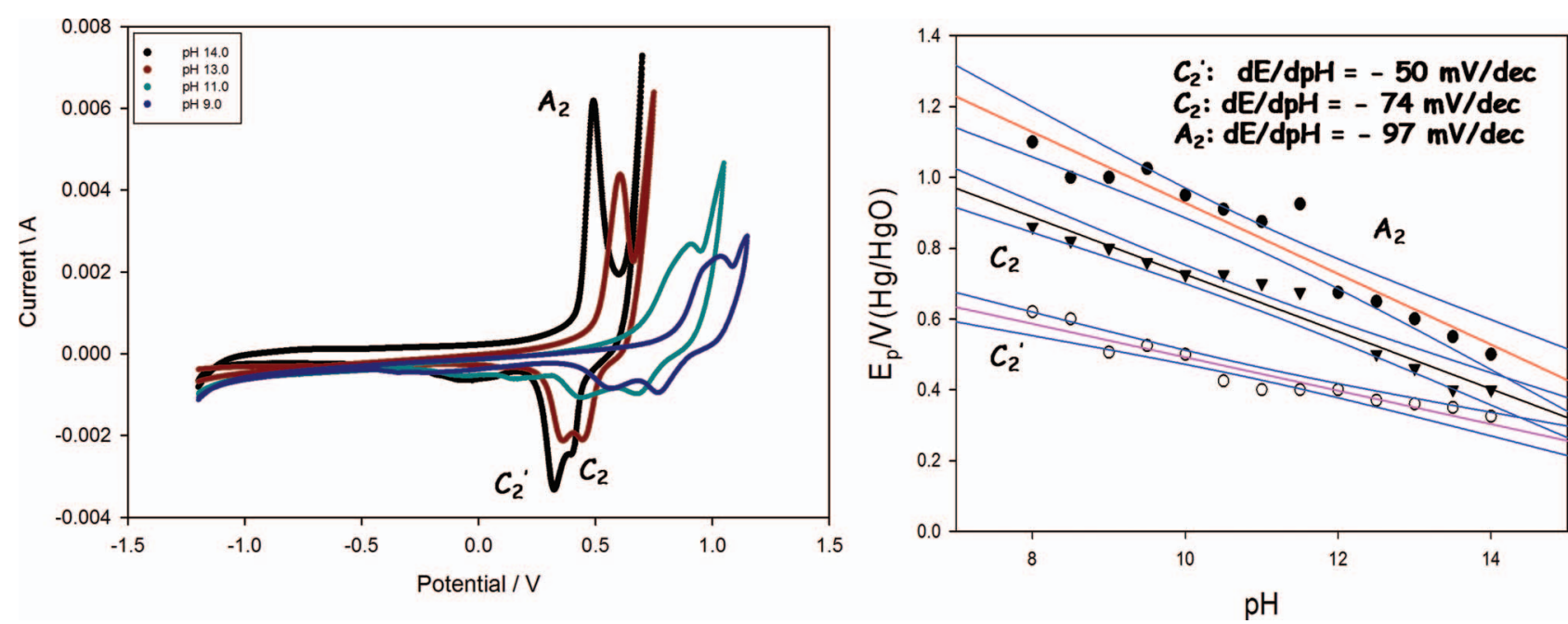

Figure 8. (a) Typical voltammetric response recorded for a hydrous nickel oxyhydroxide thin film on Ni support electrode grown in aqueous $1.0 \mathrm{M}$ NaOH for $\mathrm{N}$ $=120$ cycles. Sweep rate, $40 \mathrm{mV} / \mathrm{s}$. Voltammetry recorded in solutions of various $\mathrm{pH}$ values. (b) Variation of voltammetric peak potentials with solution pH. 


\section{Hydrous Oxide}

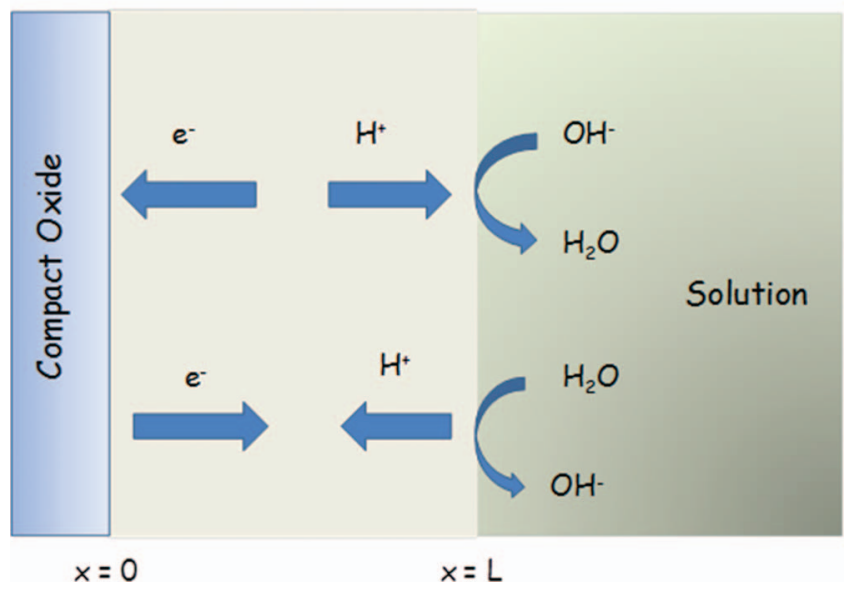

Figure 9. Schematic representation of charge/discharge redox switching mechanism occuring within the microdispersed hydrous nickel oxide layer. The thickness of the hydrous layer is L. The redox switching mechanism involves proton diffusion within the film coupled with chemical reaction at the outer interface.

by others ${ }^{40}$ to derive an expression for the inverse diffusive time constant $\tau_{D}^{-1}=D / L^{2}$. These workers solved the finite diffusion problem under conditions of a linear potential sweep. Transport information may be readily extracted from an analysis of the shape of the voltammetric response as a function of sweep rate. We have recently reported the utilization of this analysis to examine the redox switching process for multicycled iron electrodes in aqueous base. ${ }^{30}$

We will apply the most simple variant of the Aoki model and consider the situation where the charge percolation along the oxide polymer strands between adjacent $\mathrm{Ni}$ sites and the accompanying proton diffusion in the pores can be considered to be irreversible. The conditions under which the latter conditions pertain may be discerned by examining the variation of the voltammetric peak potential with sweep rate. The results of such an experiment is presented in Fig. 10. Here the cyclic voltammetric response as a function of sweep rate is examined for various hydrated nickel oxide films of varying thickness (the latter scaling with the number of potential cycles employed during the layer growth process).

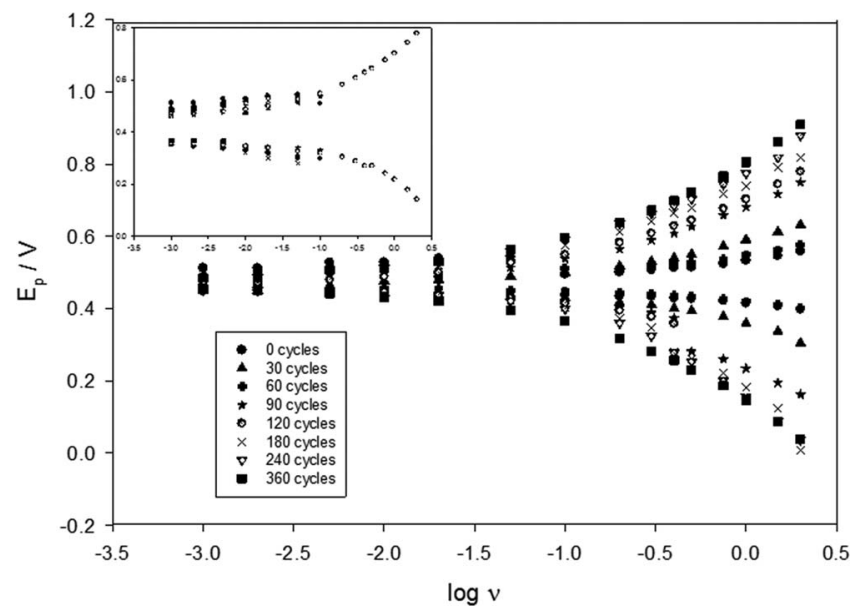

Figure 10. Variation of voltammetric peak potential with log sweep rate for a series of multicycled $\mathrm{Ni}$ electrodes in $1.0 \mathrm{M} \mathrm{NaOH}$ at $298 \mathrm{~K}$. Attention is focused on the main anodic and cathodic charge storage peaks corresponding to the $\mathrm{Ni}(\mathrm{II}) / \mathrm{Ni}(\mathrm{III})$ redox transition located at potentials prior to active oxygen evolution.

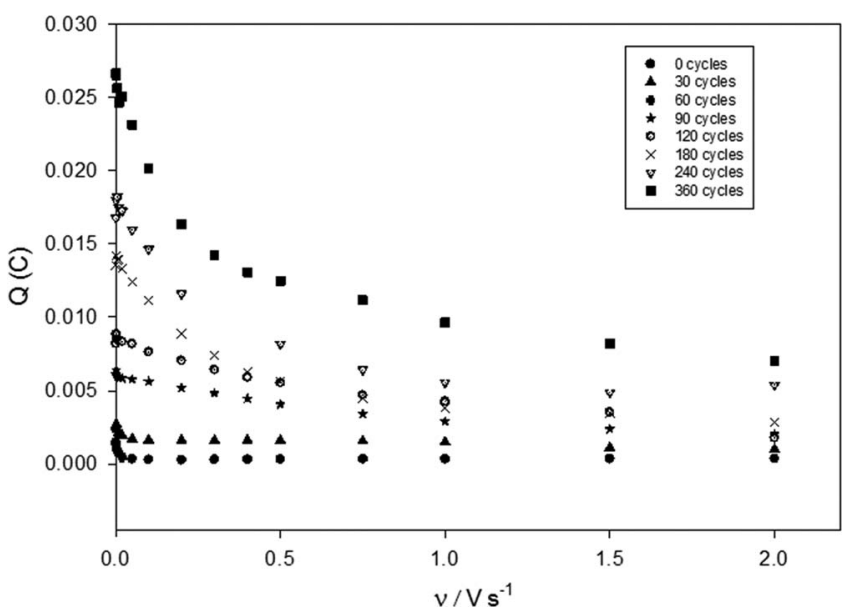

Figure 11. Variation of voltammetric redox charge capacity $Q$ with analytical sweep rate for a series of $\mathrm{Ni}$ oxide hydrous films grown under potential cycling conditions for various number of cycles. Attention is focused on the main anodic charge storage peak corresponding to the $\mathrm{Ni}(\mathrm{II}) / \mathrm{Ni}(\mathrm{III})$ redox transition located at potentials prior to active oxygen evolution.

In short, when the diffusive charge percolation process is reversible the voltammetric peak potentials will remain invariant with changes in sweep rate. In this way we define the time window in which the electrochemical reversibility pertains. We note that the peak potential begins to shift significajntly with increasing sweep rate for values greater than $1 \mathrm{~V} \mathrm{~s}^{-1}$. Between $0.3 \mathrm{~V} \mathrm{~s}^{-1}$ and $1.0 \mathrm{~V} \mathrm{~s}^{-1}$ an intermediate transition region is observed. Below $0.3 \mathrm{Vs}^{-1}$ the peak potential remains invariant with sweep rate and the redox switching reaction is regarded to be kinetically reversible.

The variation of hydrous oxide charge capacity $\mathrm{Q}$ (which is proportional to the redox charge capacity $\mathrm{C}$ defined for electroactive polymer films in the work of Murray et al..$^{41,42}$ ), with analytical sweep rate is presented in Fig. 11. We note that the recorded charge capacity values for reasonably thin oxide films (less than 60 cycles growth) remain invariant with sweep rate between $2 \mathrm{~V} \mathrm{~s}^{-1}$ and ca. $10 \mathrm{mV} \mathrm{s}^{-1}$, but then increase slightly as the sweep rate is decreased further. This trend is most marked for thicker films ( 180 cycles growth and greater). Indeed for a thick nickel oxide layer it may be noted that the charge capacity increases by nearly $50 \%$ when the sweep rate decreases from ca. $1 \mathrm{~V} \mathrm{~s}^{-1}$ to ca. $10 \mathrm{mV} \mathrm{s}^{-1}$. A similar result has been recently noted for hydrous iron oxide films in base. ${ }^{30}$

These results may be readily rationalized in terms of a simple diffusive model as previously noted. ${ }^{30}$ With thinner films there is sufficient time at normal sweep rates for the redox reaction to extend to virtually all regions of the dispersed hydrous layer, i.e. a situation of Nernstian equilibrium pertains through the hydrous film, and the redox charge capacity will be effectively independent of experimental time scale (i.e. sweep rate). However with thicker films there is not enough time (apart from the lowest sweep rates or alternatively longest time scales) for the redox reaction to propagate throughout the entire extent of the dispersed hydrous region. Thus the charge capacity values drop dramatically as the analytical sweep rate is increased.

The variation of voltammetric peak width at half peak height for the main anodic charge storage peak $\mathrm{A}_{2}$ with sweep rate is outlined in Fig. 12. We present data for a range of oxide film thicknesses. We note that in all cases examined the peak width at half peak height increases regularly with increasing sweep rate from an initial value of ca. $30 \mathrm{mV}$ at the lowest values of sweep rate to considerably larger values at higher sweep rates. Furthermore it was noted that at a particular sweep rate the peak width at half peak height increased regularly with number of potential cycles.

Lyons $^{43}$ has noted that the peak width at half peak height $\Delta E_{p / 2}$ value extracted from the voltammogram recorded for an electrode chemically modified with an electroactive polymer thin film conveys 


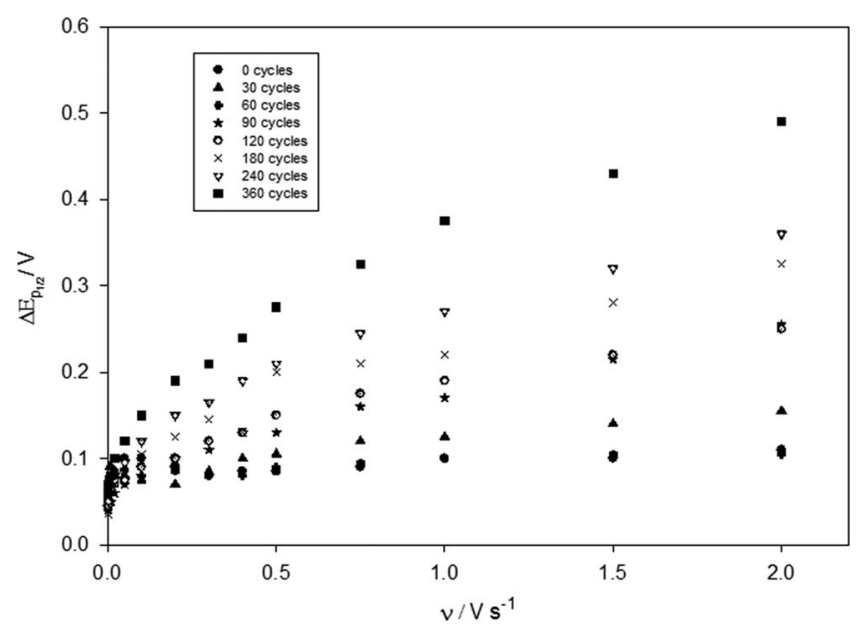

Figure 12. Variation of peak width at half peak height with sweep rate for a series of multicycled nickel electrodes in $1.0 \mathrm{M} \mathrm{NaOH}$.

very useful information about the electrochemistry of redox switching in the layer. Similar considerations arise in the present case. Laviron ${ }^{44}$ has developed a useful theory to describe redox switching within space distributed electroactive redox polymer films where charge is transferred via nearest neighbor electron hopping both intrastrand and interstrand. The analysis has been further extended by Aoki and coworkers. ${ }^{39}$ These models enable the cyclic voltammetric response to be analyzed quantitatively as a function of sweep rate. In particular these models enable a prediction to be made concerning the shape of the voltammetric response both for reversible, totally irreversible and indeed quasi-reversible redox switching reactions occuring both in monolayer and multilayer modified electrodes thin films, both in the absence of and in the presence of interactions between the participating redox centers. These models have been well described by Lyons. ${ }^{43}$ In the latter models, if it is assumed that redox switching is electrochemically reversible then the peak width at half peak height is assumed to be given by:

$$
\Delta E_{p / 2}=\frac{2 R T}{n F} \ln (3+2 \sqrt{2})=\frac{3.53 R T}{n F}
$$

Keeping in mind the representation of the $\mathrm{Ni}(\mathrm{II}) / \mathrm{Ni}(\mathrm{III})$ redox switching reaction presented in scheme A previously we can assign $\mathrm{n}=2$ and for $\mathrm{T}=298 \mathrm{~K}$ we predict that $\Delta E_{p / 2} \cong 45.3 \mathrm{mV}$ which is in excellent agreement with the experimental data recorded in Fig. 12 in the low sweep rate limit. Now in many situations it is established that voltammetric peaks are either broader or narrower than this ideal value. This observation implies that either repulsive or attractive interactions operate within the thin film. Furthermore such an occurrence signifies that either not all sites in the film have the same standard potential or thermodynamic activity effects must be considered. Occupied redox sites with repulsive interactions tend to avoid one another, which ultimately promotes an alternating site occupancy; this is essentially the same as compound formation. This effect results in a broadening of the voltammetric peak response compared with that expected ideally as outlined in eqn. 11 for a reversible reaction. In contrast when the interactions are attractive, occupied sites tend to cluster together, which leads to phase separation and considerable narrowing in the voltammogram compared with the ideal. In electroactive polymer materials the extent of peak broadening or narrowing depends to a great extent on the nature of the solvent and the identity and concentration of the charge compensating counterions.

According to $\mathrm{Aoki}^{39}$ the peak width is related to an empirical interaction parameter $\sigma$ as follows:

$$
\Delta E_{p / 2}=\frac{2 R T}{n F}\left\{\ln \left(\frac{1+\rho}{1-\rho}\right)-\rho \sigma\right\}
$$

In the latter expression we note that $\sigma=\mathrm{gc}_{\Sigma}=\mathrm{g} \Gamma / \mathrm{L}=\mathrm{G} / \mathrm{RT}$ where $g$ denotes the Temkin interaction parameter which is negative if repulsive interactions operate and positive if attractive interactions pertain, and $\mathrm{G}$ denotes the Gibbs energy of interaction between the redox sites ${ }^{2}$. Furthermore, $c_{\Sigma}=\Gamma / L$ denotes the site concentration within the hydrous layer, and $\Gamma, \mathrm{L}$ represent the surface coverage and layer thickness respectively. Furthermore we note that:

$$
\rho=\sqrt{\frac{2-\sigma}{4-\sigma}}
$$

Under reversible conditions the voltammetric peak corresponding to the redox switching reaction within the hydrous oxide layer is identical in shape to the theoretical reversible monolayer peak for reasonably slow sweep rates ${ }^{3}$. The fact that the peak width at half peak height indicates that the voltammetric peaks exhibit an increasingly more prominent 'tailing' effects as the experimental timescale decreases, in which the peaks exhibit an increasing asymmetry about E- $E_{p}$. The latter occurrence may be attributed to the fact that there is not enough time at faster sweep rates at the beginning of the scan for the redox reaction to propagate through the film. This of course is a diffusive effect.

Aoki $^{39}$ has shown that the voltammetric response for a thin film in which the redox reaction is reversible takes the following form:

$$
\begin{aligned}
i= & n F A(\Gamma / L) \sqrt{n F D v / R T} W^{1 / 2} \int_{0}^{\infty} \theta_{2}(0, y) \\
& \times \frac{\exp [W y-\xi(\tau)]}{(1+\exp [W y-\xi(\tau)])^{2}} d y \\
= & n F A(\Gamma / L) \sqrt{n F D v / R T} F(W, \xi)
\end{aligned}
$$

In the latter expression we have set:

$$
F(W, \xi)=W^{1 / 2} \int_{0}^{\infty} \theta_{2}(0, y) \frac{\exp [W y-\xi(\tau)]}{(1+\exp [W y-\xi(\tau)])^{2}} d y
$$

Furthermore, we note that:

$$
\xi(\tau)=\frac{n F}{R T}\left(E_{i}-E^{0}\right)+\frac{n F L^{2} v \tau}{R T}
$$

Also we define $\tau=D t / L^{2}$, and we introduce the Theta function as:

$$
\theta_{2}(0, y)=\frac{1}{\sqrt{\pi y}}\left\{1+2 \sum_{k=1}^{\infty}(-1)^{k} \exp \left[-\frac{k^{2}}{y}\right]\right\}
$$

We also note that the parameter $\mathrm{W}$ is given by:

$$
W=\frac{n F L^{2} v}{D R T}=\left(\frac{L}{X_{D}}\right)^{2}
$$

And the diffusion layer thickness is:

$$
X_{D}=\sqrt{\frac{D R T}{n F v}}
$$

Hence we note that the parameter $\sqrt{W}$ is simply the ratio of the layer thickness to the diffusion layer thickness in the film. Now the general expression outlined in eqn. 14 cannot be integrated analytically, so one must resort to a numerical analysis in order to compute the shape of the voltammogram. However eqn. 14 must reduce to the surface

\footnotetext{
${ }^{2}$ If $g=0$ the peak has the shape and characteristics of the ideal Langmuirian voltammetric peak. If $\mathrm{g}<0$, the peak becomes broader and flatter, and if $\mathrm{g}>0$, with $0<\mathrm{g}<2$, the peak becomes narrower and sharper. If $g>2$ a hysteresis phenomenon is exhibited and the peaks can no longer be described mathematically.

${ }^{3}$ This is given by the expression $\Psi=\operatorname{sech}^{2}[\xi / 2]=\exp [-\xi] /(1+\exp [-\xi])^{2}$ where the normalized current response is given by $\Psi=i /\left(n F^{2} A \Gamma v / R T\right)$ and the normalized potential is $\xi=n F\left(E-E^{0}\right) / R T$.
} 
voltammetic limit when $\mathrm{W}$ is small and to the semi-infinite RandlesSevcik limit when the parameter $\mathrm{W}$ is large. Hence:

$$
\begin{aligned}
& \lim _{W \rightarrow 0}\left\{W^{-1 / 2} F(W, \xi)\right\} \rightarrow \frac{\exp [-\xi]}{(1+\exp [-\xi])^{2}} \int_{0}^{\infty} \theta_{2}(0, y) d y \\
& \rightarrow \frac{\exp [-\xi]}{(1+\exp [-\xi])^{2}}
\end{aligned}
$$

The result presented in eqn. 20 is obtained since we note that:

$$
\begin{aligned}
\int_{0}^{\infty} \theta_{2}(0, y) d y & =\lim _{p \rightarrow 0}\left\{L\left(\theta_{2}(0, \tau)\right)\right\} \\
& =\lim _{p \rightarrow 0}\left\{p^{-1 / 2} \tanh [\sqrt{p}]\right\}=1
\end{aligned}
$$

Where $\mathrm{p}$ is the Laplace parameter. Furthermore if $\mathrm{W}$ is large enough such that semi-infinite diffusion conditions pertain, then in this case we can show that the Theta function in eqn. 17 reduces to:

$$
\theta_{2}(0, y) \cong \frac{1}{\sqrt{\pi y}}
$$

And the expression for the current reduces to:

$$
i \cong n F A(\Gamma / L) \sqrt{\frac{n F D \pi}{R T}} v \int_{0}^{\infty} \frac{\exp [W y-\xi]}{(1+\exp [W y-\xi])^{2}} y^{-1 / 2} d y
$$

This integral equation is essentially similar in form to that derived many years ago by Nicholson and Shain and others. ${ }^{45,46}$ The latter integral may be evaluated numerically and we may readily show that the peak current is given by:

$$
i_{p}=0.4463 n F A \Gamma \sqrt{\frac{n F}{R T}}\left(\frac{D}{L^{2}}\right)^{1 / 2} v^{1 / 2}
$$

This is the well established Randles-Sevcik expression characteristic of semi-infinite diffusion. Hence the diffusive time constant $\tau_{D}=D / L^{2}$ can be evaluated from the slope of the Randles-Sevcik plot.

The variation of voltammetric peak current with square root sweep rate for a series of multicycled $\mathrm{Ni}$ electrodes in $1.0 \mathrm{M} \mathrm{NaOH}$ is outlined in Fig. 13. We note good Randles-Sevcik linearity at lower sweep rates but the current response begins to level out at higher sweep rates. This type of leveling out in the current response at high sweep rates can be predicted from the Aoki analysis. ${ }^{39}$ In particular, using a numerical analysis it has been shown that the peak current, $i_{p}$, representing the main redox switching process in the hydrated layer varies with $v$ according to,

$$
i_{p}=0.446 n F A\left\{\Gamma D / L^{2}\right\} W^{1 / 2} \tanh [\Upsilon]
$$

In the latter expression we note that:

$$
\Upsilon=0.56 \sqrt{W}+0.05 W
$$

and we recall that $\mathrm{W}$ is defined via eqn. 18 . This expression may be re-cast in a non-dimensional format to produce a working curve as follows:

$$
\Psi=\frac{i_{p}}{n F A(\Gamma / L)}\left\{\frac{R T}{n F D v}\right\}^{1 / 2}=0.446 \tanh [\Upsilon]
$$

The diffusive frequency $\tau_{D}=D / L^{2}$ can be readily evaluated via numerical analysis of eqn. 25 via the following expression:

$$
G\left(\tau_{D}\right)=\alpha \tau_{D}^{1 / 2} \tanh \left\{\beta \tau_{D}^{1 / 2}+\frac{\gamma}{\tau_{D}}\right\}-i_{p}=0
$$

In the latter expression we have set:

$$
\begin{aligned}
& \alpha=0.446 \frac{(n F)^{3 / 2}}{(R T)^{1 / 2}} A \Gamma v^{1 / 2} \\
& \beta=0.56 \sqrt{\frac{n F v}{R T}} \\
& \gamma=0.05\left(\frac{n F v}{R T}\right)
\end{aligned}
$$

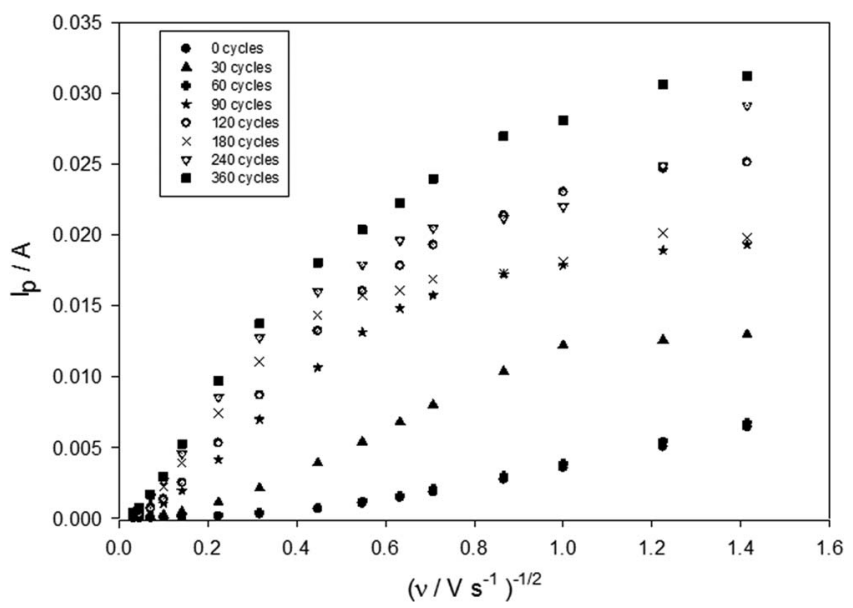

Figure 13. Typical Randles-Sevcik plots recorded for a series of multicycled $\mathrm{Ni}$ electrodes in $1.0 \mathrm{M} \mathrm{NaOH}$ as a function of number of oxide growth cycles.

The roots $\tau_{D}$ of the non-linear expression $G\left(\tau_{D}\right)=0$ can be obtained from a standard numerical protocol such as the Bisection algorithm. ${ }^{47}$ Hence the diffusive frequency $\tau_{D}=D / L^{2}$ can be evaluated provided the peak current $i_{p}$ and surface coverage $\Gamma$ are known at a particular sweep rate $v$. Furthermore if the layer thickness $L$ can be estimated then the diffusion coefficient $\mathrm{D}$ can be evaluated.

We have used both eqn. 28 and a Randles-Sevcik analysis to numerically evaluate the diffusive frequency $\tau_{D}=D / L^{2}$. The results are compared graphically in Fig. 14 for a series of multi-cycled $\mathrm{Ni}$ electrodes. We see that similar results are obtained using the two procedures. The diffusive frequency decreases smoothly with increasing number of oxide growth cycles $\mathrm{N}$ from a value close to $1.0 \mathrm{~s}^{-1}$ for the thinnest nickel oxyhydroxide films to ca. $0.2 \mathrm{~s}^{-1}$ for layers formed after ca. 360 cycles. We also have not estimated the layer thickness L in order to compute a charge transfer diffusion coefficient given the approximations and uncertainties inherent in layer thickness estimation. Instead we are content to deal with the diffusive frequency given by $\tau_{D}=D / L^{2}$.

We conclude that the Aoki analysis (bearing its intrinsic limitations in mind) provides a very useful approximate model to obtain quantitative redox switching information form perusal of cyclic voltammetry data as a function of sweep rate.

OER kinetics and mechanism. - In this section we describe the results of a comprehensive kinetic analysis carried out at hydrous oxide

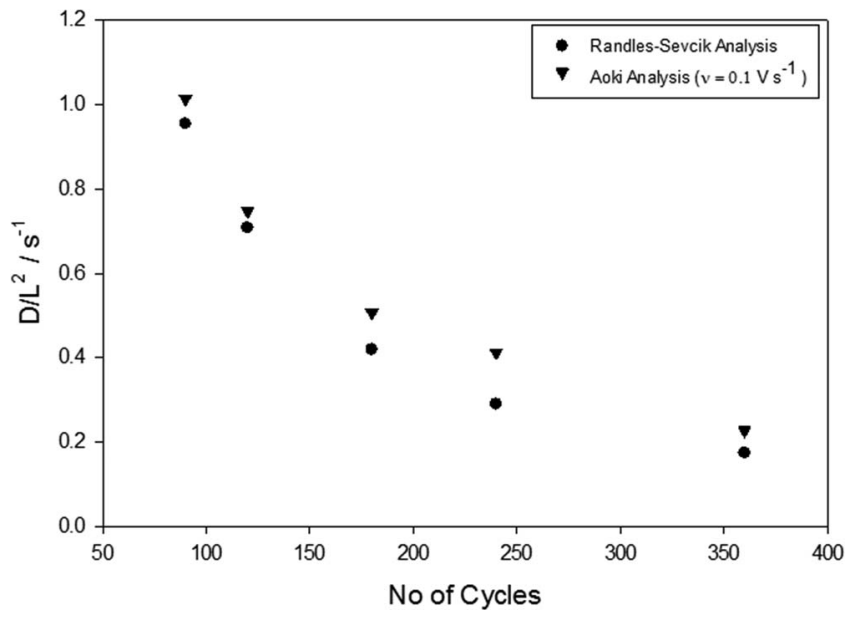

Figure 14. Variation of diffusive frequency characterizing redox switching in multicycled hydrous oxide coated $\mathrm{Ni}$ electrodes in $1.0 \mathrm{M} \mathrm{NaOH}$ with number of oxide growth cycles. 


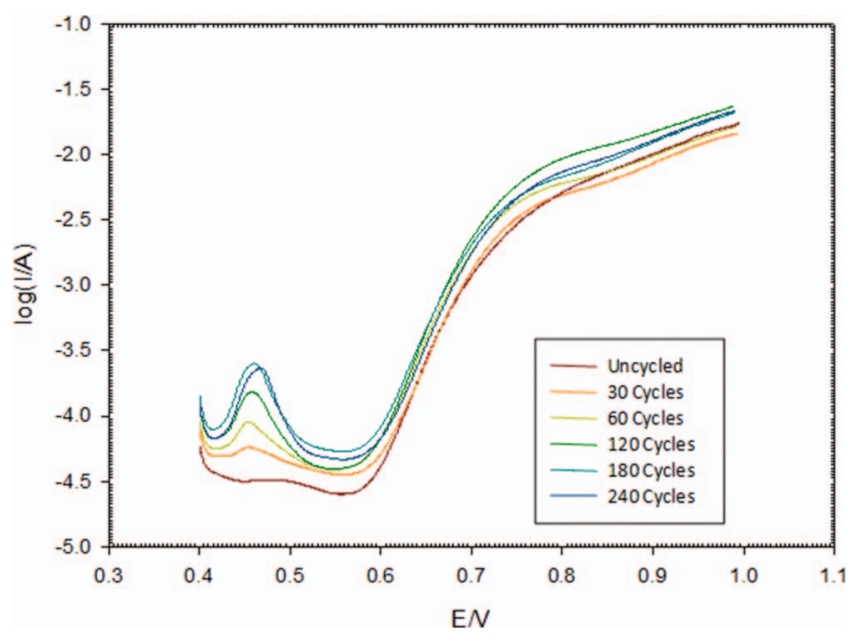

Figure 15. Typical steady state polarization curves (iR corrected) for active oxygen evolution at a series of multicycled $\mathrm{Ni}$ electrodes in $1.0 \mathrm{M} \mathrm{NaOH}$ solution at $298 \mathrm{~K}$.

coated Ni electrodes in aqueous alkaline solution. These studies were performed both as a function of base concentration and hydrous oxide layer thickness. These studies follow on from a recently published paper $^{30}$ which describes enhanced oxygen evolution at hydrous oxyhydroxide modified iron electrodes in aqueous alkaline solution. We also refer to an earlier paper written by Lyons and Brandon ${ }^{8}$ which describes the OER mechanism and kinetics at oxidized (but not potential multicycled) $\mathrm{Ni}$ electrodes in base.

Typical steady state polarization curves for the OER recorded at a series of multicycled $\mathrm{Ni}$ electrodes in $1.0 \mathrm{M} \mathrm{NaOH}$ solutions are outlined in Fig. 15. It is clear from these plots that the slope of the linear Tafel region located between $0.6 \mathrm{~V}$ and $0.7 \mathrm{~V}$ remains invariant with oxide charge capacity (the latter being related to the number of oxide growth cycles). Furthermore the current recorded at a given potential increases with increasing oxide charge capacity and the potential recorded at a fixed current decreases with increasing oxide charge capacity.

These points are further outlined in Fig. 16 presented below where the variation with oxygen evolution rate (measured at a number of fixed overpotentials in the linear Tafel region) with average hydrous oxide charge capacity is presented. Tafel slopes (measured in $1.0 \mathrm{M} \mathrm{NaOH}$ ) were found to vary between $55-80 \mathrm{mV} \mathrm{dec}^{-1}$ over the range of oxide charge capacities examined. Typically as illustrated in

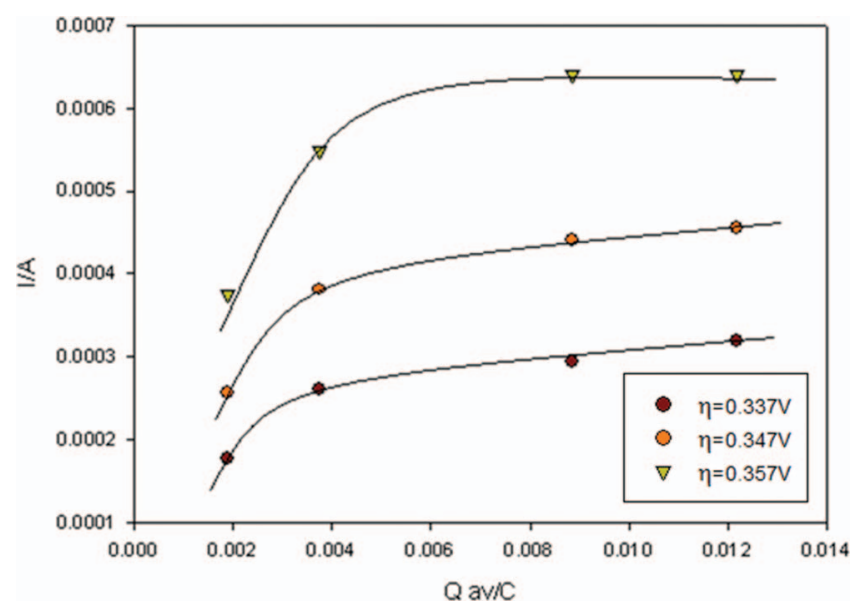

Figure 16. Variation of OER current recorded at a series of fixed overpotentials in the linear Tafel region as a function of average oxide charge capacity Q. Tafel plots were recorded in $1.0 \mathrm{M} \mathrm{NaOH}$.

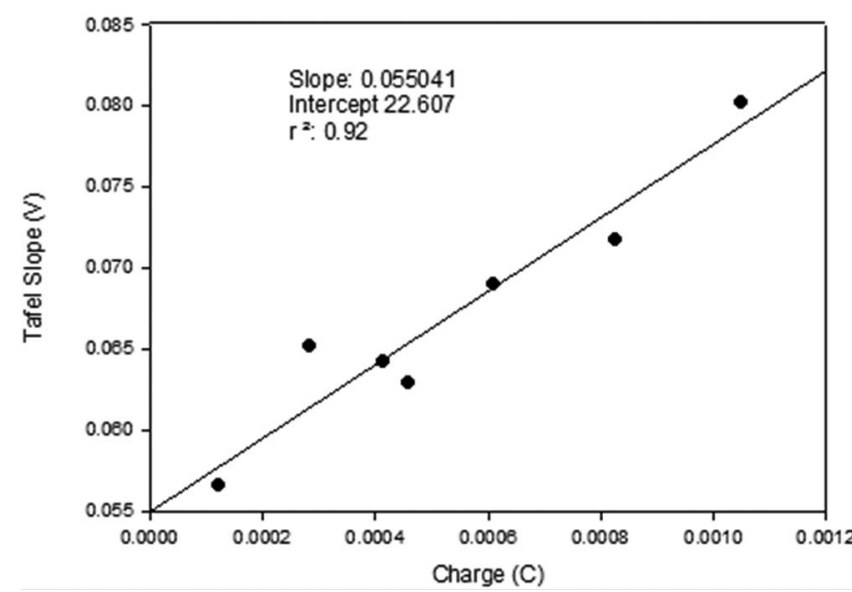

Figure 17. Variation of OER Tafel slopes recorded at low overpotentials with hydrous oxide charge capacity value $\mathrm{Q}$. Tafel plots were recorded in $1.0 \mathrm{M}$ $\mathrm{NaOH}$.

Fig. 17, the Tafel slope recorded at low potentials increases in a regular manner with increasing oxide charge capacity from a low of ca. $57 \mathrm{mVdec}^{-1}$ to a high of ca. $80 \mathrm{mVdec}^{-1}$.

Typical steady state Tafel plots were also recorded as a function of base concentration over an extended range of the latter. The results for a thin film $(\mathrm{N}=30$ oxide growth cycles $)$ are presented in Fig. 18 and those for a somewhat thicker layer $(\mathrm{N}=120$ cycles $)$ are illustrated in Fig. 19. In both cases Tafel slopes close to ca. $60 \mathrm{mV} \mathrm{dec}^{-1}$ are noted at low potentials and close to ca. $120 \mathrm{mV} \mathrm{dec}^{-1}$ at higher potentials.

A series of reaction order studies were performed both in the low and high Tafel slope regions for thin and thicker hydrous oxide layers. The results are presented in Figures 20 and 21 below. For the thinner oxide films the reaction orders were $m_{\mathrm{OH}^{-}}=\left(\frac{d \log i}{d \log a_{\mathrm{OH}^{-}}}\right)=1.02$ in the low Tafel slope region and $m_{\mathrm{OH}^{-}}=0.93$ in the high Tafel slope region. The corresponding values recorded for thicker films were $m_{\mathrm{OH}^{-}}=0.85$ and $m_{\mathrm{OH}^{-}}=0.82$ in the low and high Tafel slope regions respectively.

Hence any mechanism must rationalize a dual Tafel slope behavior and a constant reaction order with respect to $\mathrm{OH}^{-}$ion activity of unity irrespective of overpotential. In summary, a kinetic analysis and associated reaction mechanism for the OER at both the uncycled and multicycled $\mathrm{Ni}$ electrodes considered in this article, must predict that

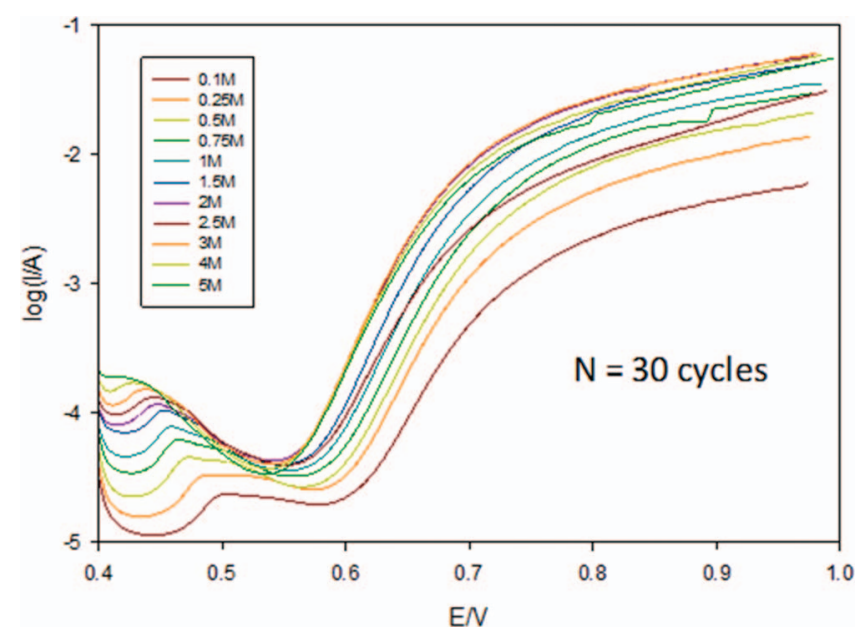

Figure 18. Typical Tafel plots for active oxygen evolution recorded for a hydrous oxide coated $\mathrm{Ni}$ electrode $(\mathrm{N}=30$ growth cycles in $1.0 \mathrm{M} \mathrm{NaOH})$ as a function of base concentration. 


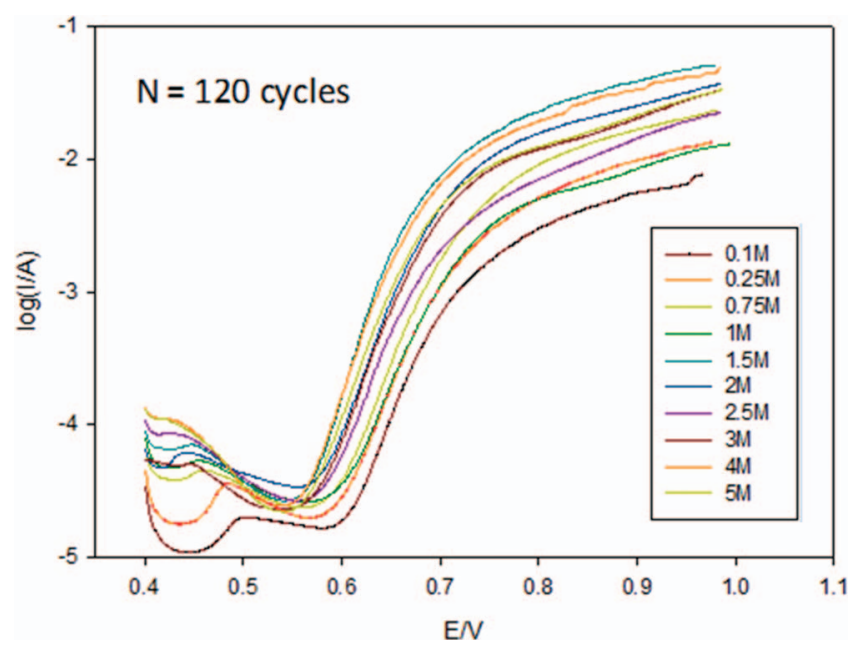

Figure 19. Typical Tafel plots for active oxygen evolution recorded for a hydrous oxide coated $\mathrm{Ni}$ electrode $(\mathrm{N}=120$ growth cycles in $1.0 \mathrm{M} \mathrm{NaOH})$ as a function of base concentration.

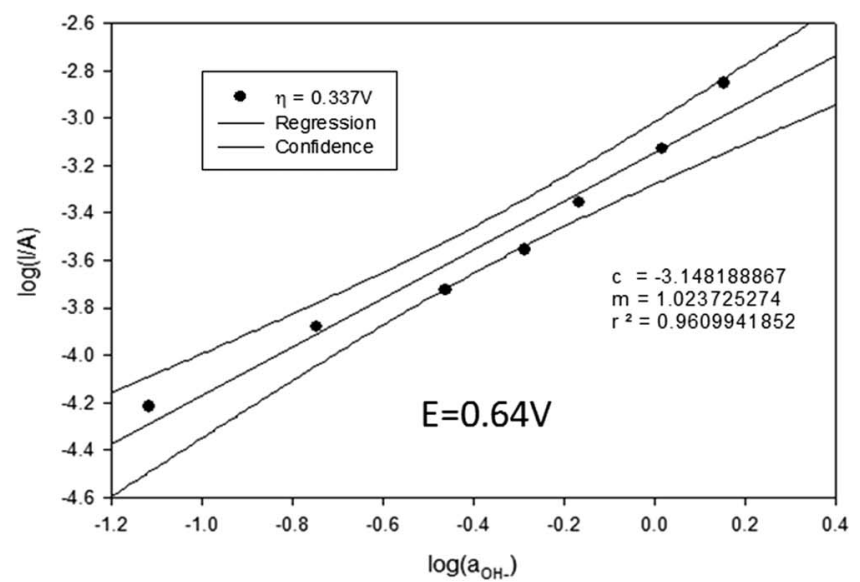

(a)

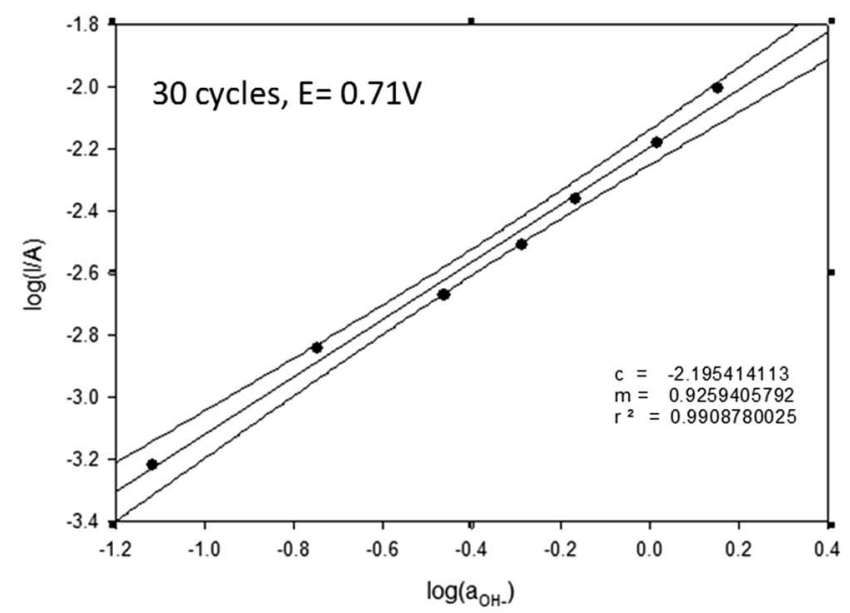

(b)

Figure 20. (a) Typical Reaction order with respect to Oxygen evolution recorded for a thin hydrous oxide coated $\mathrm{Ni}$ electrode $(\mathrm{N}=30$ oxide growth cycles, $1.0 \mathrm{M} \mathrm{NaOH})$ in (a) the low Tafel slope region $(\mathrm{E}=0.64 \mathrm{~V}$ or $\eta$ $=0.337 \mathrm{~V}) ;(\mathrm{b})$ the high Tafel slope region $(\mathrm{E}=0.71 \mathrm{~V}$ or $\eta=0.407 \mathrm{~V})$.

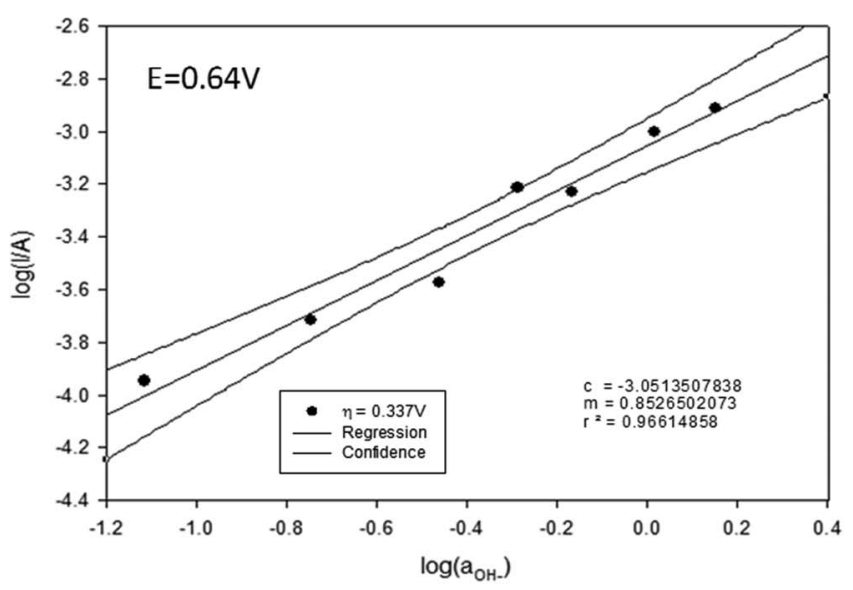

(a)

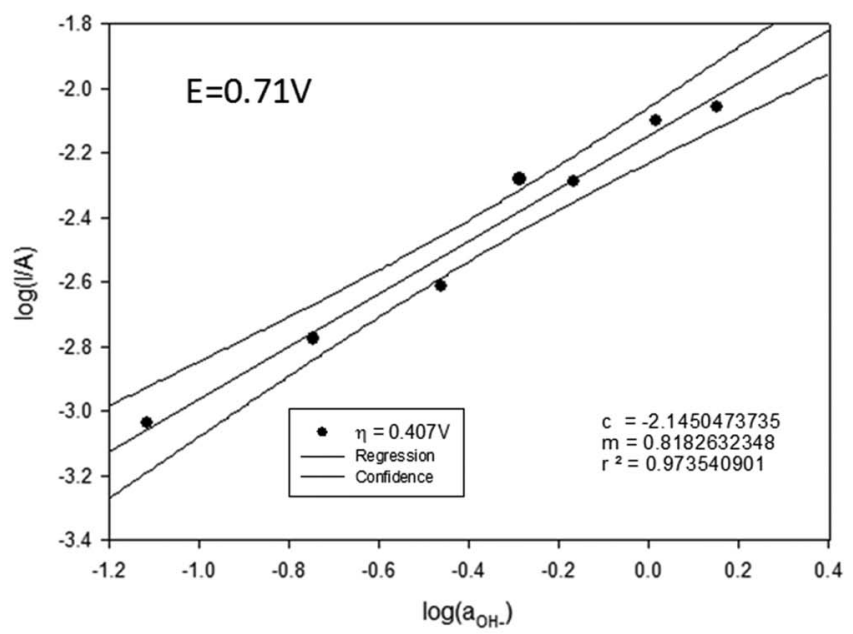

(b)

Figure 21. Typical Reaction order with respect to Oxygen evolution recorded for a thin hydrous oxide coated $\mathrm{Ni}$ electrode $(\mathrm{N}=120$ oxide growth cycles, $1.0 \mathrm{M} \mathrm{NaOH})$ in (a) the low Tafel slope region $(\mathrm{E}=0.64 \mathrm{~V}$ or $\eta=0.337 \mathrm{~V})$; (b) the high Tafel slope region $(\mathrm{E}=0.71 \mathrm{~V}$ or $\eta=0.407 \mathrm{~V})$.

$b=2.303 \times R T / F$ and the reaction order $m_{\mathrm{OH}^{-}}=1$ at low potentials, changing to $b=2.303 \times 2 R T / F$ and $m_{O H^{-}}=1$ at higher potentials.

In a recent communication ${ }^{21}$ we suggested that the following represents a plausible mechanism to account for the reported kinetic data for the OER at multicycled $\mathrm{Ni}$ electrodes in aqueous base:

$\left[\mathrm{Ni}(\mathrm{III}) \mathrm{O}_{\mathrm{m}}(\mathrm{OH})_{\mathrm{n}}\right]^{\mathrm{p}-}+\mathrm{OH}^{-} \rightarrow\left[\mathrm{Ni}(\mathrm{III}) \mathrm{O}_{\mathrm{m}}(\mathrm{OH})_{\mathrm{n}}\left(\mathrm{OH}^{*}\right)\right]^{\mathrm{p}^{-}}+\mathrm{e}^{-}[30]$

$$
\left[\mathrm{Ni}(\mathrm{III}) \mathrm{O}_{\mathrm{m}}(\mathrm{OH})_{\mathrm{n}}\left(\mathrm{OH}^{*}\right)\right]^{\mathrm{p}-} \rightarrow\left[\mathrm{Ni}(\mathrm{III}) \mathrm{O}_{\mathrm{m}}(\mathrm{OH})_{\mathrm{n}+1}\right]^{\mathrm{p}-}
$$

$\left[\mathrm{Ni}(\mathrm{III}) \mathrm{O}_{\mathrm{m}}(\mathrm{OH})_{\mathrm{n}+1}\right]^{\mathrm{p}-} \rightarrow\left[\mathrm{Ni}(\mathrm{III}) \mathrm{O}_{\mathrm{m}}(\mathrm{OH})_{\mathrm{n}-1}\right]^{(\mathrm{p}-1)-}--\mathrm{H}_{2} \mathrm{O}_{2}+\mathrm{e}^{-}$

$$
\begin{aligned}
& {\left[\mathrm{Ni}(\mathrm{III}) \mathrm{O}_{\mathrm{m}}(\mathrm{OH})_{\mathrm{n}-1}\right]^{(p-1)-}--\mathrm{H}_{2} \mathrm{O}_{2}+2 \mathrm{OH}^{-}} \\
& \quad \rightarrow\left[\mathrm{Ni}(\mathrm{III}) \mathrm{O}_{\mathrm{m}}(\mathrm{OH})_{\mathrm{n}}\right]^{\mathrm{p}-}--\mathrm{HO}_{2}+\mathrm{H}_{2} \mathrm{O}+\mathrm{e}^{-}
\end{aligned}
$$

$$
\begin{aligned}
& {\left[\mathrm{Ni}(\mathrm{III}) \mathrm{O}_{\mathrm{m}}(\mathrm{OH})_{\mathrm{n}}\right]^{\mathrm{p}-}--\mathrm{HO}_{2}+\mathrm{OH}^{-}} \\
& \quad \rightarrow\left[\mathrm{Ni}(\mathrm{III}) \mathrm{O}_{\mathrm{m}}(\mathrm{OH})_{\mathrm{n}}\right]^{\mathrm{p}-}+\mathrm{O}_{2}+\mathrm{H}_{2} \mathrm{O}+\mathrm{e}^{-}
\end{aligned}
$$

This mechanism involves the invocation of a $\mathrm{Ni}$ (III) oxidation state throughout and does not suggest the formation of a $\mathrm{Ni}(\mathrm{IV})$ state. We represent the mechanistic sequence in terms of linked networked octahedral surfaquo groups in an extended microdisperse open polymeric framework in which the central metal ion $(\mathrm{M}=\mathrm{Ni}$ (III)) is coordinated to hydroxyl $(\mathrm{OH})$, oxide $(\mathrm{O})$ and water $\left(\mathrm{OH}_{2}\right)$ ligands. The 


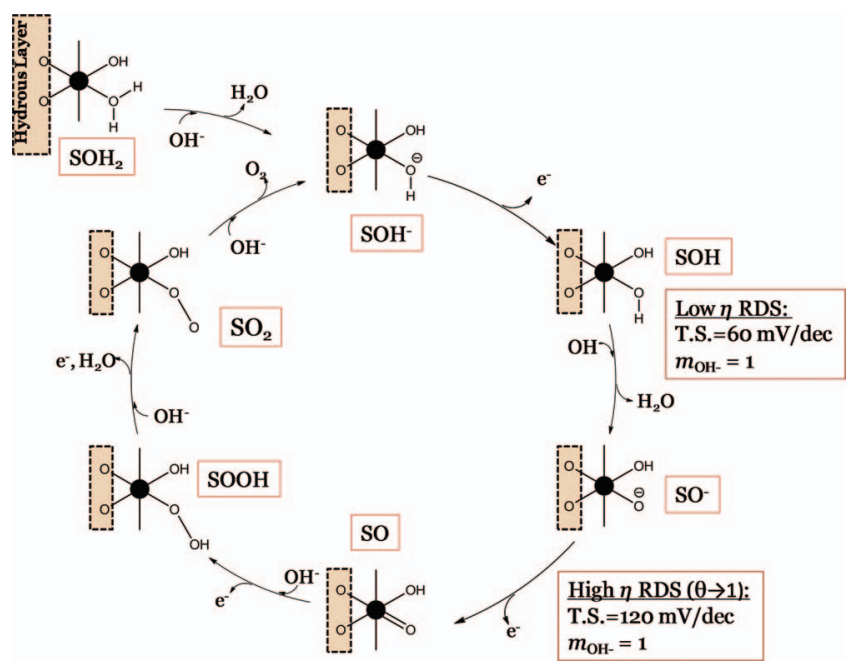

Scheme B. OER mechanism involving surfaquo groups in the hydrous oxynickel hydroxide layer.

second non-eletrochemical step (eqn. 31) in the reaction sequence is rate determining at low overpotentials and the initial discharge step (eqn. 30) becomes rate limiting at high overpotentials. The latter expression involves the relaxation of a coordinated $\mathrm{OH}$ ligand between two energetically inequivalent positions (labeled $\mathrm{OH}^{*}$ and $\mathrm{OH}$ ). This mechanism is similar to that recently outlined by us for hydrous oxide coated Fe electrodes in aqueous base. ${ }^{8,10,30}$ Again we note that $\mathrm{p}=2 \mathrm{~m}$ $+\mathrm{n}-3$, and the rate limiting second step again involves a structural rearrangement of an energetically in-equivalent coordinated hydroxyl ligand. Following Bockris and Otagawa, ${ }^{48}$ we also invoke the formation of a physisorbed peroxide entity $\mathrm{S}-\mathrm{H}_{2} \mathrm{O}_{2}$. Note that in the step presented in eqn. 32 the electron lost to the external circuit is provided by an excess co-ordinated $\mathrm{OH}^{-}$ion, leading to an overall decrease of one unit in the net negative charge of the surface complex. The suggestion that the OER mechanism involves a NI(III) hydroperoxy intermediate of the form $\mathrm{S}-\mathrm{HO}_{2}{ }^{-}$is attractive and has received some experimental backing from recent spectroscopic measurements. ${ }^{49}$ In the scheme outlined in eqn. 30-34 above the catalytically active intermediate species are represented as complex anionic entities, in agreement with the observed acid/base properties of the hydrated oxide film. We believe that this approach is more realistic than thinking in terms of discrete simple stoichiometric oxy-hydroxide species.

We now wish to extend this mechanistic analysis and develop a more comprehensive mechanism which is in excellent agreement with the kinetic data. Our mechanistic thinking is guided by the earlier work of Kobussen and Broers. ${ }^{50}$ The mechanism is presented in schematic form in Scheme B. Note that octahedrally co-ordinated oxy-nickel surfaquo groups are identified as the catalytically active species and are located within the hydrous layer. The following reaction sequence based on Scheme B may be outlined:

$$
\begin{gathered}
\mathrm{SOH}_{2}+\mathrm{OH}^{-} \rightarrow \mathrm{SOH}^{-}+\mathrm{H}_{2} \mathrm{O} \\
\mathrm{SOH}^{-} \rightarrow \mathrm{SOH}+e^{-} \\
\mathrm{SOH}+\mathrm{OH}^{-} \rightarrow \mathrm{SO}^{-}+\mathrm{H}_{2} \mathrm{O} \\
\mathrm{SO}^{-} \rightarrow \mathrm{SO}+e^{-} \\
\mathrm{SO}+\mathrm{OH}^{-} \rightarrow \mathrm{SOOH}+e^{-} \\
\mathrm{SOOH}_{+} \mathrm{OH}^{-} \rightarrow \mathrm{SO}_{2}+\mathrm{H}_{2} \mathrm{O}+e^{-} \\
\mathrm{SO}_{2}+\mathrm{OH}^{-} \rightarrow \mathrm{SOH}^{-}+\mathrm{O}_{2}
\end{gathered}
$$

In the latter scheme $S$ represents the surfaquo group which is attached to the hydrous oxide surface by bridging oxygen ligands.
The proposed catalytic cycle for the OER outlined in Scheme $\mathrm{B}$, involves an octahedrally coordinated $\mathrm{Ni}(\mathrm{III})$ species located in the hydrous layer. This scheme is analogous to those depicted for various different photocatalyst systems. ${ }^{51-53}$ A common feature of these schemes is that the starting point for the OER catalytic cycle is usually represented as a metal coordinated water molecule. However, in the strongly alkaline conditions used in this system it is likely that a significant proportion of these coordinated water molecules will be deprotonated. The $\mathrm{pK}_{\mathrm{a}}$ value for a water molecule coordinated to a highly charged metal atom is generally in the range $\mathrm{pK}_{\mathrm{a}} 5-9 .{ }^{54} \mathrm{In}$ light of this, it is more reasonable to assume that the initial deprotonation step is facile and will occur outside of the catalytic cycle. Hence, the initial deprotonation step is depicted as a pre-step in Scheme B and the OER catalytic cycle begins with the resultant coordinated $\mathrm{OH}^{-}$ion which we label $\mathrm{SOH}^{-}$. A second point of note regarding Scheme $\mathrm{B}$ is that the formation of the metal oxide $\mathrm{SO}^{-}$(eqn. 37) and metal oxo $\mathrm{SO}$ (eqn. 38) species are designated as rate determining. Interestingly, in a recent theoretical study Muckermann et al. ${ }^{55}$ showed, through the use of DFT calculations, that for a $\mathrm{GaN} / \mathrm{ZnO}$ surface with high coverage of adsorbed $\mathrm{OH}^{-}$ions the intermediate associated with the highest energy was an oxide radical. Similarly, Rossmeisl et al. ${ }^{56}$ performed a DFT study of the OER at $\mathrm{RuO}_{2}$ surfaces. They too found, for a surface saturated with adsorbed $\mathrm{OH}$, that the highest energy intermediate was a surface oxygen species, in this case an oxo species. Considering these studies, the present mechanistic interpretation brings together a number of strands in the current understanding of the OER at metal oxides, and is clearly more satisfying than our previous presentation.

We note that the first step in the reaction sequence (eqn. 35) occurs rapidly and need not be included in the steady state kinetic analysis. If we assume that the step outlined in eqn. 37 is rate determining then the net reaction flux is given by:

$$
f_{\Sigma}=i / 4 F A=k_{2} a_{O H^{-}} \Gamma_{S O H}
$$

In the latter expression $a_{O H^{-}}$represents the activity of hydroxyl ion and $\Gamma$ denotes the surface coverage. We use the quasi steady state approximation to evaluate the surface coverage of $\mathrm{SOH}$ as follows:

$$
\frac{d \Gamma_{S O H}}{d t}=k_{1}^{\prime} \Gamma_{S O H^{-}}-k_{-1}^{\prime} \Gamma_{S O H}-k_{2} \Gamma_{S O H} a_{O H^{-}} \cong 0
$$

We may readily solve to obtain an expression for the surface coverage:

$$
\Gamma_{\mathrm{SOH}} \cong k_{1}^{\prime} \Gamma_{\mathrm{SOH}^{-}} /\left(k_{-1}^{\prime}+k_{2} a_{\mathrm{OH}^{-}}\right)
$$

Hence the net flux is given by

$$
f_{\Sigma} \cong \frac{k_{2} k_{1}^{\prime} a_{O H^{-}} \Gamma_{S O H^{-}}}{k_{-1}^{\prime}+k_{2} a_{O H^{-}}}
$$

In the latter expression the primed quantities represent heterogeneous electrochemical rate constants whose potential dependence is assumed to be given by the Butler-Volmer rate equation:

$$
k_{n}^{\prime}=k_{n}^{0} \exp [\beta F \eta / R T], k_{-n}^{\prime}=k_{-n}^{0} \exp [-(1-\beta) F \eta / R T]
$$

In this expression $\eta$ denotes the overpotential and $\beta$ is the symmetry factor. In contrast the chemical rate constant is given by its standard value and there is no potential dependence:

$$
k_{n}=k_{n}^{0}
$$

Hence the net flux is given by

$$
f_{\Sigma} \cong \frac{k_{2}^{0} a_{O H^{-}} \Gamma_{S O H^{-}} k_{1}^{0} \exp [\beta F \eta / R T]}{k_{-1}^{0} \exp [-(1-\beta) F \eta / R T]+k_{2}^{0} a_{O H^{-}}}
$$

Now if the step outlined in eqn. 37 is rate determining then we can safely assume that $k_{2}^{0} \ll k_{-1}^{0}$ and so eqn. 48 reduces to

$$
f_{\Sigma} \cong k_{2}^{0} \Gamma_{S O H^{-}} a_{O H^{-}}\left(k_{1}^{0} / k_{-1}^{0}\right) \exp [F \eta / R T]
$$

This expression can be readily shown to predict a reaction order of unity with respect to hydroxide ion activity and a Tafel slope at $298 \mathrm{~K}$ of ca. $60 \mathrm{mV} / \mathrm{dec}(b=2.303 R T / F)$. 
In contrast, if the subsequent step outlined in eqn. 38 becomes rate limiting then we can write that

$$
f_{\Sigma} \cong k_{3}^{\prime} \Gamma_{S O^{-}}
$$

Again using the quasi-steady state approximation we can show that

$$
\frac{d \Gamma_{S O^{-}}}{d t}=k_{2} \Gamma_{\mathrm{SOH}_{\mathrm{H}}} a_{\mathrm{OH}^{-}}-k_{-2} a_{\mathrm{H}_{2} \mathrm{O}} \Gamma_{\mathrm{SO}^{-}}-k_{3}^{\prime} \Gamma_{\mathrm{SO}^{-}} \cong 0
$$

Solving for the surfaquo group coverage we obtain

$$
\Gamma_{\mathrm{SO}^{-}} \cong k_{2}^{0} \Gamma_{\mathrm{SOH}} a_{\mathrm{OH}^{-}} /\left(k_{-2}^{0} a_{\mathrm{H}_{2} \mathrm{O}}+k_{3}^{0} \exp [\beta F \eta / R T]\right)
$$

Hence the net reaction flux is given by

$$
f_{\Sigma} \cong \frac{k_{2}^{0} k_{3}^{0} a_{O H^{-}} \Gamma_{S O H} \exp [\beta F \eta / R T]}{k_{-2}^{0} a_{H_{2} O}+k_{3}^{0} \exp [\beta F \eta / R T]}
$$

Now at high overpotentials we assume that $\Gamma_{S O H} \cong 1$ and also $k_{-2}^{0} \gg k_{3}^{0}$ and so we obtain that

$$
f_{\Sigma} \cong k_{3}^{0} a_{H_{2} O}^{-1}\left(k_{2}^{0} / k_{-2}^{0}\right) a_{O H^{-}} \exp [\beta F \eta / R T]
$$

Hence when the electrochemical oxo generation step is rate limiting at high overpotentials the flux expression presented in eqn. 54 predicts that a reaction order of unity with respect to hydroxyl ion activity and a Tafel slope of ca. $120 \mathrm{mV} /$ decade at $298 \mathrm{~K}$ will be observed $b \cong 2.303(2 R T / F)$ assuming that $\beta \cong 1 / 2$. Hence the kinetic analysis is in excellent agreement with experiment.

The observation that the Tafel slope observed at low overpotentials increases with increasing hydrous oxide charge capacity is directly at variance with similar experiments performed with multicycled iron oxide electrodes in aqueous base solution. ${ }^{30}$ We are currently examining this result in detail and will report on our conclusions in a subsequent communication.

The increase in OER current (recorded at fixed driving force or overpotential) with increasing oxide redox charge capacity as outlined in Fig. 16 is not to be unexpected since the real surface area of the oxide is increasing and consequently the number of catalytically active surfaquo groups available to participate in the oxygen evolution process is also increasing. We recall from the kinetic analysis that the oxygen evolution rate is directly proportional to $\Gamma$ the surface concentration of $\mathrm{Ni}(\mathrm{III})$ surfaquo groups (at least for low values of the redox charge capacity), and so the data outlined in Fig. 16 is not surprising.

\section{Conclusions}

In the present paper we have described the growth of hydrous nickel oxyhydroxide thin films on $\mathrm{Ni}$ substrates in aqueous base and examined the dynamics of redox switching in the latter films. A novel mechanism involving a nickel oxo intermediate in excellent agreement with experimental data has been developed which is in excellent agreement with recent spectroscopic and DFT studies.

A number of important conclusions arise from the present paper. First, hydrous microdispersed oxides are readily prepared via the repetitive cyclic potential sweep method applied to the parent metal in aqueous alkaline solution. The latter method is very similar to that employed in the electropolymerization of Electronically Conducting Polymer (ECP) films such as poly(pyrrole) or poly(aniline). The oxide/solution interface has a duplex character, consisting of an inner, largely anhydrous compact oxide, and an outer, hydrated microdisperse oxide layer which exhibits significant electrocatalytic activity with respect to anodic oxygen evolution. Second, the charge storage/charge percolation properties of the hydrous oxide depend on electrochemical and environmental variables such as the lower and upper potential sweep limits, the potential sweep rate, the base concentration employed, the solution temperature, and the solution $\mathrm{pH}$. Third, the acid/ base behavior of anodically formed transition metal oxides is important when considering the mechanism of both redox switching and oxygen evolution. Furthermore, hydrous oxides are more difficult to reduce than less hydrated compact materials, and this may well have a significant implication for the catalysis of the cathodic ORR. Fourth, we have examined the redox switching kinetics at hydrated nickel oxide in some detail and utilized theoretical models originally developed to describe transport and kinetics in polymer modified electrodes, to probe the diffusion of protons/hydroxyl ions through the hydrated oxide matrix. A diffusive frequency corresponding to protonic diffusion through the oxide was extracted via this analysis. Fifth an OER mechanism in keeping with current ideas derived from experiments on molecular inorganic transition metal complexes for OER catalysts has been proposed. This extends the classic work of Kobussen and Broers ${ }^{50}$ and utilizes the concept of a surfaquo groups involving a metal oxide and metal oxo species as participants in the rate determining step of the oxygen evolution reaction under electrochemical conditions. Indeed we can conclude that the chemistry of the surfaquo group determines the chemistry of the OER catalytic cycle.

\section{Acknowledgments}

This paper is dedicated to the memory of Professor Laurence D Burke, Fellow of the Electrochemical Society, late of the Department of Chemistry, University College, Cork, Ireland who has recently passed away. Professor Burke was a first rate scientist and an excellent mentor and friend to many. The field of Physical Electrochemistry is much the poorer for his absence. He will be sorely missed.

This publication has emanated in part from research conducted with the financial support of Science Foundation Ireland (SFI) under grant Number SFI/10/IN.1/I2969.

\section{References}

1. (a) D. E. Hall, J. Electrochem. Soc., 130, 317 (1983); (b) K. Zeng and D. Zhang, Prog. Energy Combust. Sci., 36, 307 (2010); (c) H. Tributsch, Int. J. Hydrogen Energy, 33, 5911 (2008); (d) G. W. Crabtree, M. S. Dresselhaus, and M. V. Buchanan, Phys. Today, December 2004, 39.

2. K. Kinoshita, Electrochemical Oxygen Technology, chapter 2, pp. 78-99 WileyInterscience, New York (1992).

3. P. W. T. Lu and S. Srinivasan, J. Electrochem. Soc., 125, 1416 (1978)

4. B. E. Conway and P. L. Bourgault, Can. J. Chem., 37, 292 (1959).

5. B. E. Conway and P. L. Bourgault, Trans. Faraday Soc., 58, 593 (1962)

6. R. D. Armstrong, G. W. D. Briggs, and E. A. Charles, J. Appl. Electrochem., 18, 21 (1988).

7. E. B. Castro, S. G. Real, and L. F. Pinheiro Dick, Int. J. Hydrogen Energy., 29, 255 (2004).

8. M. E. G. Lyons and M. P. Brandon, Int. J. Electrochem. Sci., 3, 1386 (2008)

9. M. E. G. Lyons and M. P. Brandon, Int. J. Electrochem Sci., 3, 1425 (2008).

10. M. E. G. Lyons and M. P. Brandon, Int. J. Electrochem. Sci., 3, 1463 (2008).

11. P. He and L. R. Faulkner, Anal. Chem., 58, 517 (1986).

12. M. E. G. Lyons and L. D. Burke, J. Electroanal. Chem., 170, 377 (1984).

13. L. D. Burke and M. E. G. Lyons, J. Electroanal. Chem., 198, 347 (1986).

14. M. E. G. Lyons and M. P. Brandon, Phys. Chem. Chem. Phys., 11, 2203 (2009).

15. L. D. Burke, M. E. Lyons, and O. J. Murphy, J. Electroanal. Chem., 132, 247 (1982).

16. L. D. Burke, M. I. Casey, V. J. Cunnane, O. J. Murphy, and T. A. M. Twomey, J. Electroanal. Chem., 189, 353 (1985).

17. P. He and L. R. Faulkner, Anal. Chem., 58, 517 (1986).

18. S. Gottesfeld and S. Srinivasan, J. Electroanal. Chem., 86, 89 (1978).

19. L. D. Burke and D. P. Whelan, J. Electroanal. Chem., 109, 385 (1980).

20. A. C. Chialvo, W. E. Triaca, and A. J. Arvia, J. Electroanal. Chem., 146, 93 (1983).

21. M. E. G. Lyons, L. Russell, M. O'Brien, R. L. Doyle, I. Godwin, and M. P. Brandon, Int. J. Electrochem. Sci., 7, 2710 (2012).

22. (a) L. D. Burke and T. A. M. Twomey, J. Electroanal. Chem., 162, 101 (1984); (b) L. D. Burke and T. A. M. Twomey, J. Electroanal. Chem., 167, 285 (1984)

23. L. M. M. de Souza, F. P. Kong, F. R. McLarnon, and R. H. Muller, Electrochim. Acta, 42, 1253 (1997)

24. L. D. Burke and M. E. G. Lyons, Mod. Asp. Electrochem., 18, 169 (1986).

25. S. D. James, J. Electrochem. Soc., 116, 1681 (1969).

26. J. W. Schultze and K. H. Vetter, Electrochim. Acta, 18, 889 (1973)

27. W. M. Sachtler and L. L. V. Reizen, J. Res. Inst. Catal., Hokkaido Univ., 10, 87 (1962).

28. R. Woods, in Electroanal. Chem., Vol. 9, Ed. A. J. Bard, Marcel Dekker, New York, 1976, Ch. 1.

29. L. D. Burke and E. J. M. O'Sullivan, J. Electroanal. Chem., 117, 155 (1981).

30. M. E. G. Lyons, R. L. Doyle, and M. P. Brandon, Phys. Chem. Chem. Phys., 13, 21530 (2011)

31. L. D. Burke and D. P. Whelan, J. Electroanal. Chem., 162, 121 (1984). 
32. (a) D. M. MacArthur, J. Electrochem. Soc., 117, 422 (1970); (b) D. M. MacArthur, J. Electrochem. Soc., 117, 729 (1970).

33. A. H. Zimmerman and P. K. Effa, J. Electrochem. Soc., 131, 709 (1984).

34. (a) J. W. Weidner and P. Timmerman, J. Electrochem. Soc., 141, 346 (1994); (b) S. Motupally, C. C. Streinz, and J. W. Weidner, J. Electrochem. Soc., 142, 1401 (1995).

35. Z. Mao, P. De Vidts, R. E. White, and J. Newman, J. Electrochem. Soc., 141, 54 (1994).

36. M. Wehrens-Dijksma and P. H. L. Notten, Electrochim. Acta, 51, 3609 (2006).

37. M. S. Kim and K. B. Kim, J. Electrochem. Soc., 145, 507 (1998).

38. G. T. Cheek and W. E. O'Grady, J. Electroanal. Chem., 421, 173 (1997).

39. (a) K. Aoki, K. Tokuda, and H. Matsuda, J. Electroanal. Chem., 146, 417 (1983); (b) K. Aoki, K. Tokuda, and H. Matsuda, J. Electroanal. Chem., 160, 33 (1984).

40. V. Mirceski and Z. Tomovski, J. Solid State Electrochem., 15, 197 (2011).

41. R. W. Murray, in Molecular Design of Electrode Surfaces, Ed. R. W. Murray, Techniques of Chemistry Series, Wiley Interscience, New York, 1992, vol. 22, ch. 1, pp. $1-48$.

42. (a) J. C. Jernigan, C. E. D. Chidsey, and R. W. Murray, J. Am. Chem. Soc., 107, 2824 (1985); (b) C. E. D. Chidsey and R. W. Murray, J. Phys. Chem., 90, 1479 (1986); (c) E. F. Dalton, N. A. Surridge, J. C. Jernigan, K. O. Wilbourne, J. S. Facci, and R. W. Murray, Chem. Phys., 141, 143 (1990); (d) J. C. Jernigan, N. A. Surridge, M. E. Zvanut, M. Silver, and R. W. Murray, J. Phys. Chem., 93, 4620 (1989).

43. M. E. G. Lyons, Electroactive Polymer Electrochemistry, Plenum Press, New York, 1994, ch.2, pp. 102-103.

44. (a) E. Laviron, J. Electroanal. Chem., 52, 395 (1974); (b) E. Laviron, J. Electroanal Chem., 112, 1 (1980); (c) E. Laviron, L. Roullier, and C. Degrand, J. Electroanal.
Chem., 112, 11 (1980); (d) E. Laviron, J. Electroanal. Chem., 122, 37 (1981); (e) E. Laviron and L. Roullier, J. Electroanal. Chem., 115, 65 (1980); (f) E. Laviron, J. Electroanal. Chem., 101, 19 (1979).

45. R. S. Nicholson and I. Shain, Anal. Chem., 36,706 (1964).

46. (a) J. M. Saveant, Electrochem. Acta, 12, 999 (1967); (b) R. S. Nicholson and I. Shain, Anal. Chem., 37, 178 (1965); (c) W. H. Reinmuth, Anal. Chem., 34, 1446 (1962).

47. W. H. Press, S. A. Teukolsky, W. T. Vetterling, and B. P. Flannery, Numerical Recepies, 2nd Edition, Cambridge University Press, Cambridge, UK, 1993, Chap. 9, pp. 343-346.

48. J. O' M. Bockris and T. Otagawa, J. Phys. Chem., 87, 2960 (1983).

49. (a) B. S. Yeo, S. L. Klaus, P. N. Ross, R. A. Mathies, and A. T. Bell, ChemPhysChem, 11, 1854 (2010); (b) B. S. Yeo and A. T. Bell, J. Am. Chem. Soc., 133(14), 5587 (2011).

50. A. G. C. Kobussen and G. H. J. Broers, J. Electroanal. Chem., 126, 221 (1981).

51. M. Busch, E. Ahlberg, and I. Panas, Phys. Chem. Chem. Phys., 13, 15069 (2011).

52. L.-P. Wang, Qin Wu, and T. Van Voorhis, Inorg. Chem., 49, 4543 (2010).

53. L. Duan, F. Bozoglian, S. Mandal, B. Stewart, T. Privalov, A. Llobet, and L. Sun, Nature, 4, 418 (2012).

54. G. A. Lawrence, Introduction to Coordination Chemistry, p. 199, J. Wiley \& Sons, West Sussex (2010).

55. X. Shen, Y. A. Small, J. Wang, P. B. Allen, M. V. Fernandez-Serra, M. S. Hybertsen, and J. T. Muckerman, J. Phys. Chem., 114, 13695 (2010).

56. J. Rossmeisl, Z.-W. Qu, H. Zhu, G.-J. Kroes, and J. K. Norskov, J. Electroanal. Chem., 607, 83 (2007). 